مجلة الاقتصاد المنزلي - مجلد 28 ـ العدد الرابع 2018

\footnotetext{
المؤتمر الدولى الستصاد - العربى العشرون للاقتصاد المنزلى

Economics

http://homeEcon.menofia.edu.eg $\quad$ ISSN 1110-2578
}

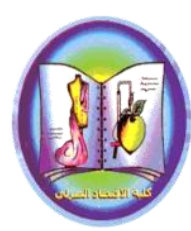

\title{
الاستفادة من معالجة الأقمشة متعددة الوظائف بمواد صديقة للبيئة في تنفيذ ملابس الأطفال
}

\author{
ماجدة ابراهيم متولي الأسود ، إيمان رأفت فريد ابو السعود \\ مدرس بقسم الملابس والنسيج - كلية الاقتصاد المنزلى - جامعة المنيل المنوفية المنية
}

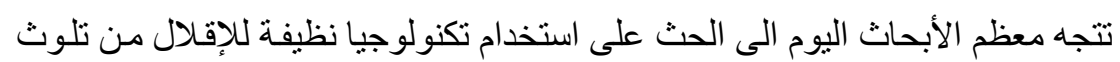

\section{الملخص}

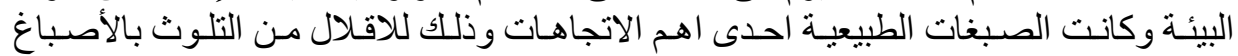

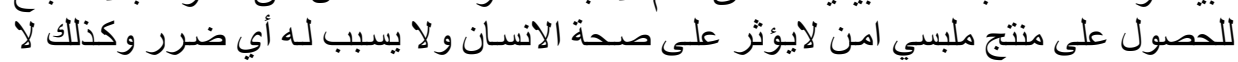

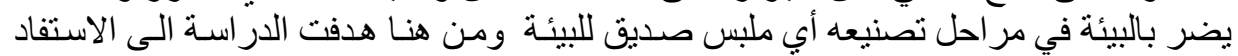

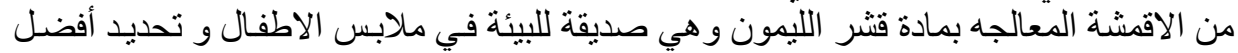

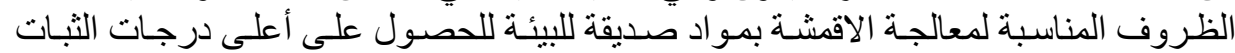

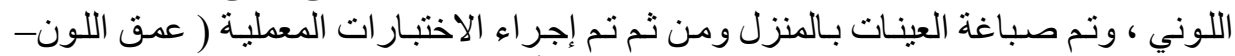

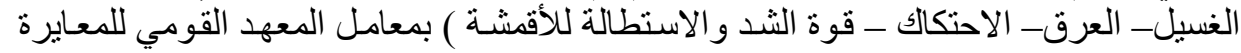

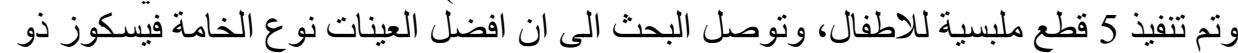

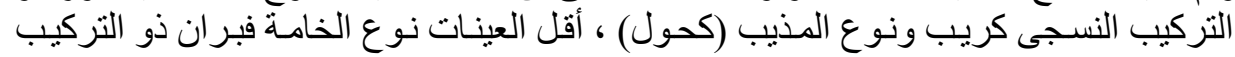

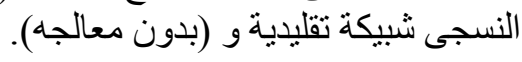

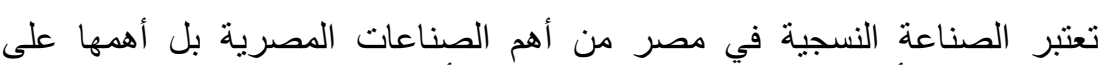

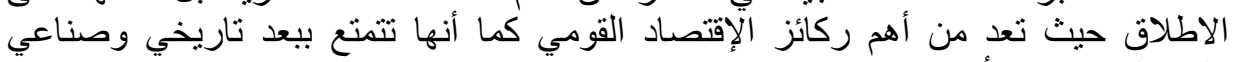

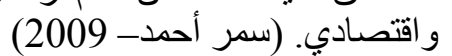

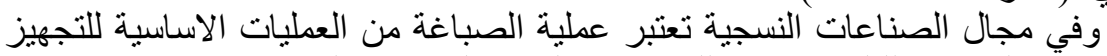

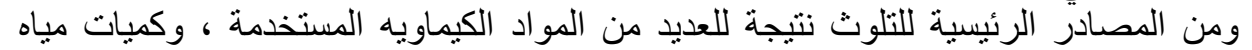

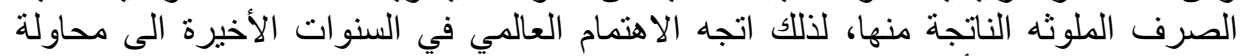

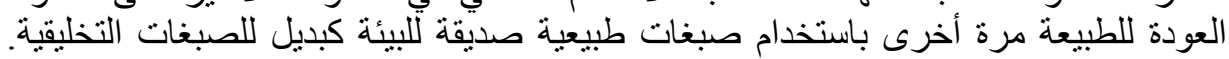

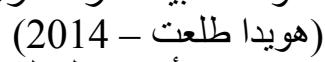
و أخذت كل الثركات العالمية تعمل بشدة على زيادة تحقيق المو اصفات القياسية للمنتج

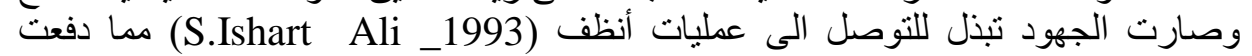

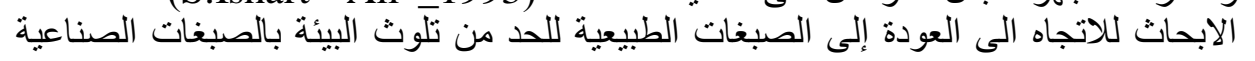




\section{مجلة الاقتصاد المنزلي - مجلد 28 ـ العدد الرابع 2018}

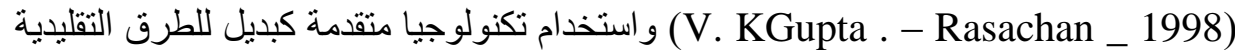
(John and Margaret Connon-1994)

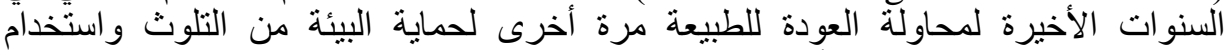
الصبغات الطبيعية الني هي أكثر صداقة للبيئة كبديل للصبئة الصغات الصناعية ( Fleischer

(Guenter-1995

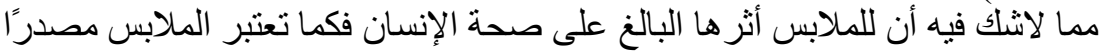

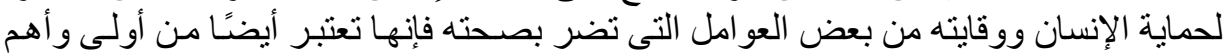

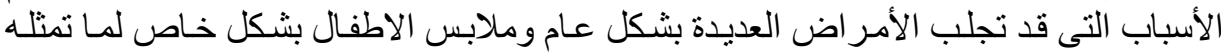

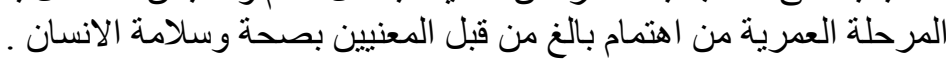

$$
\text { مشكلة البحث :- تتحدد مشكلة البحث في التساؤلات الأتية }
$$

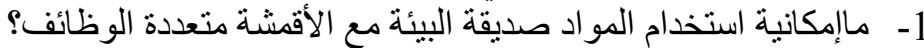

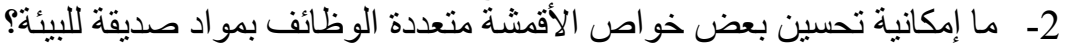

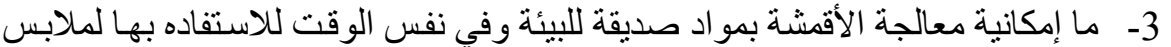

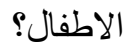

$$
\begin{aligned}
& \text { هاف البحث : يهدف البحث الى الى الى }
\end{aligned}
$$

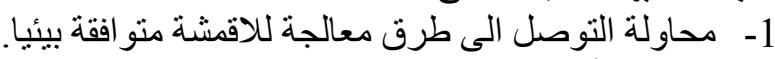

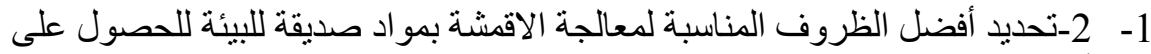

$$
\begin{aligned}
& \text { أعلى درجات الثبات اللوني. } \\
& \text { 2- الاستفاد من الاقمشة المعالجه بمو اد صديقة البيئة في ملابس الاطفال. } \\
& \text { أهمية البحث : بسعى البحث الى الى الى }
\end{aligned}
$$

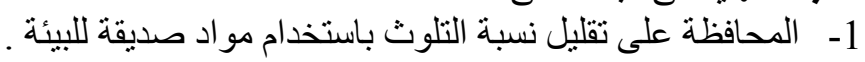

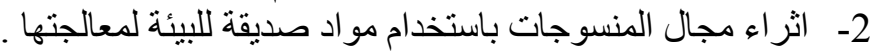

$$
\begin{aligned}
& \text { 3- مو اكبة الاتجاه العالمي نحو المحافظه على البيئة. }
\end{aligned}
$$

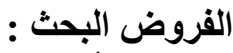

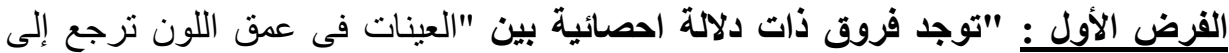

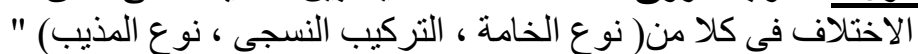

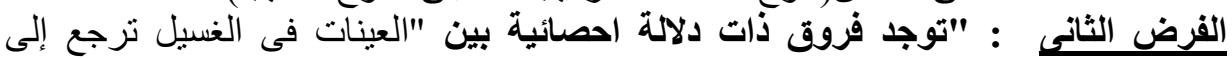

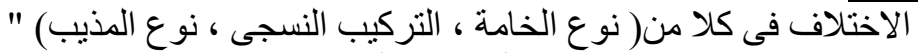

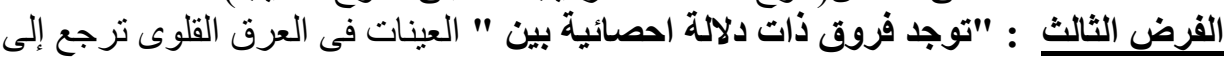

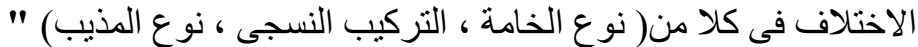

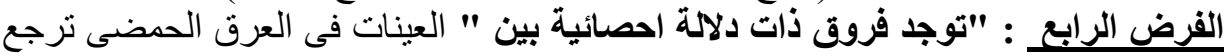

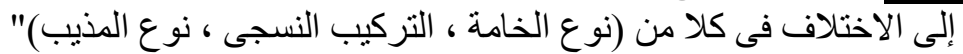




\section{مجلة الاقتصاد المنزلي - مجلد 28 - العدد الرابع 2018}

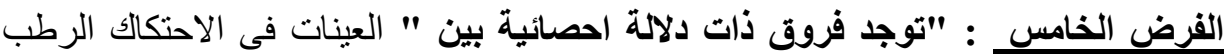

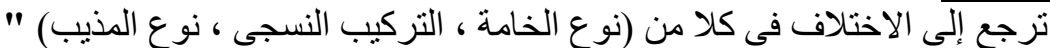

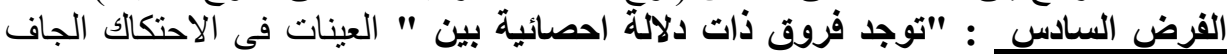

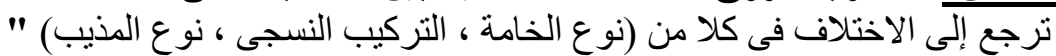

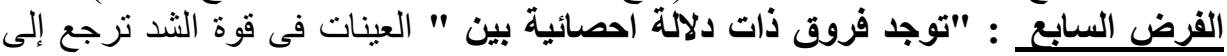

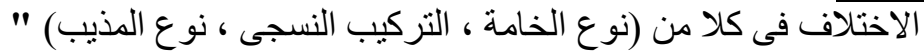

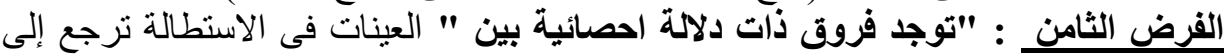

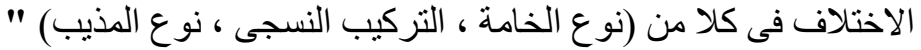

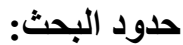

استخدام ثلاث أنواع من الأقمشة (قطن 100\% - فسكوز 100\% - فبران 100\%)

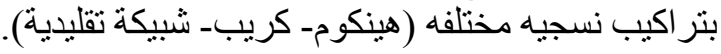
تم عمل عينات كل عينة بطول 25سم ×25سم.

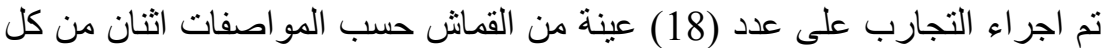

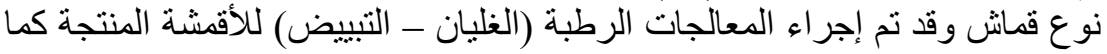
هو منبع بالثركة. إجر اء الاختبارات المعملية ( عمق اللون- الغسيلـ- العرق_ الاحتكاك ـ قوة الثند و الاستطالة للأقمشة ). تتفيذ عدد (5) قطع ملبسية للأطفال(سالوبيت_بافتهـ قفاز اتـ غطاء رأسـ لكلوك)

$$
\text { منهجج الداراسة: }
$$

المواد صديقة البيئة :Eco-friendly:

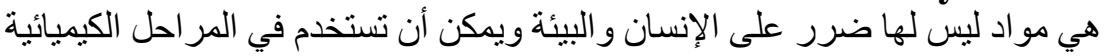

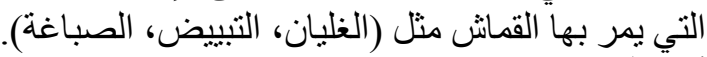
أقمشة متعددة الوظائف multifunctional fabrics : هي أقشة لها خو اص متعدده ويمكن استخدامها في أغر اض مختلفه.

الاراسات السابقة: تعرضت العديد من الدراسات السابقة الى معالجة الأقمشة بمواد صديقة

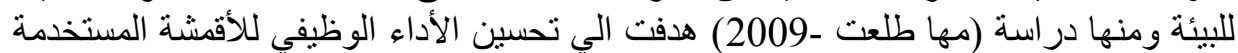

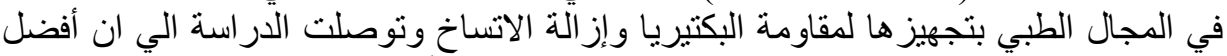

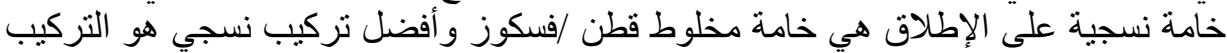

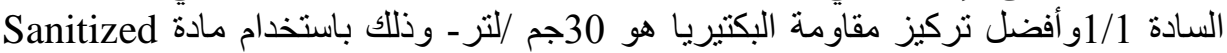

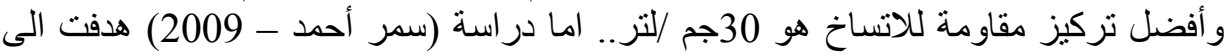




\section{مجلة الاقتصاد المنزلي - مجلد 28 - العدد الرابع 2018}

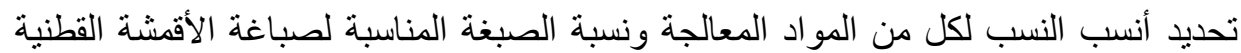

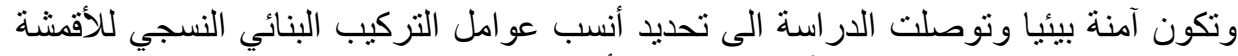

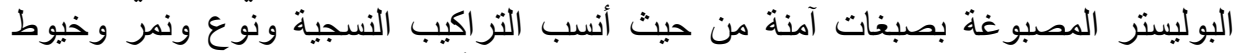

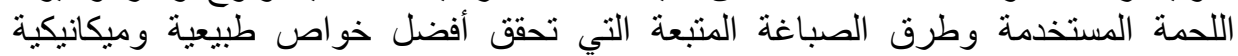

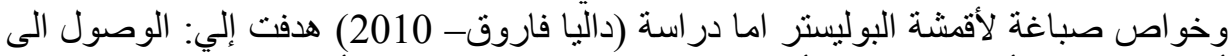

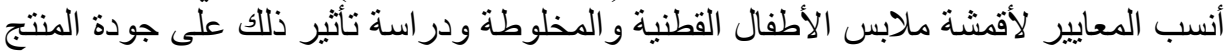

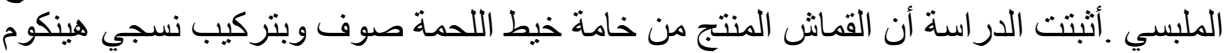

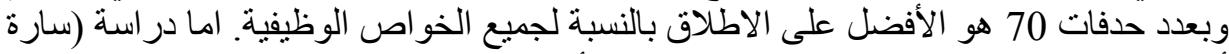

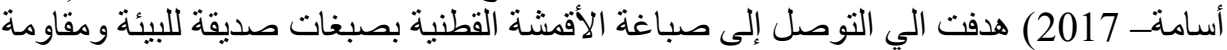

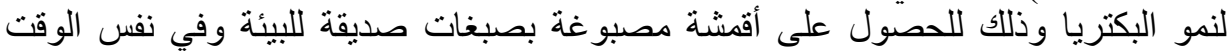

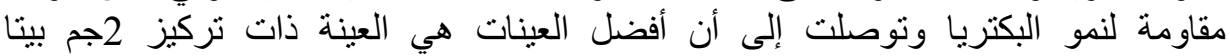

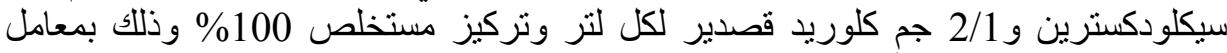

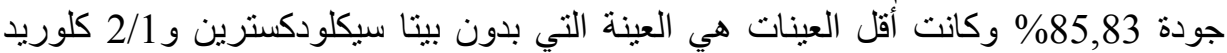

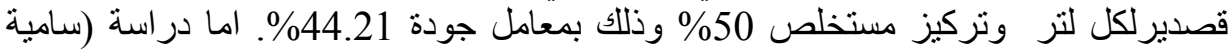

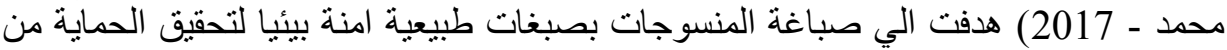

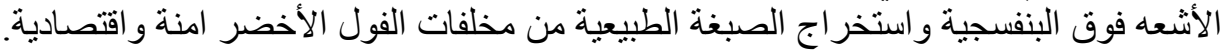

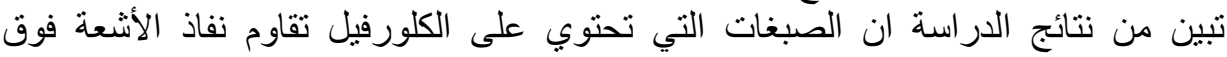

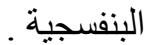

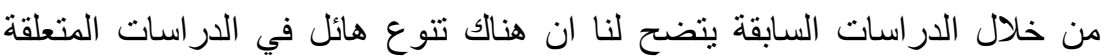

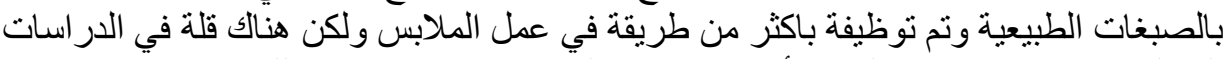

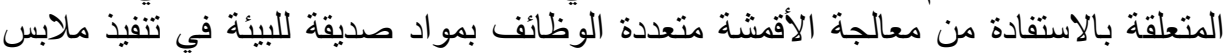

وتخدم الاراسات السابقة الاراسة الحالية في تحديد المواد المعالجة والصبة والصبغة

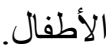

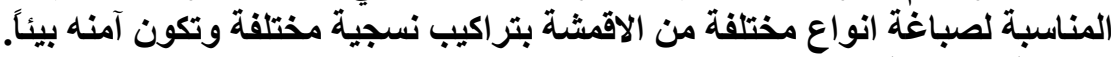

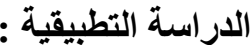

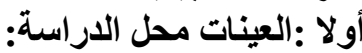

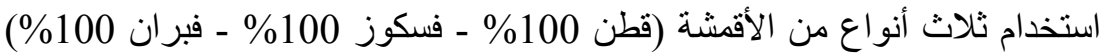
بتر اكيب نسجيه مختلفه (هينكو م- كريب- شبيكة الأن تقليدية) تم عمل عينات كل عينة بطول 25سم ×25سم.

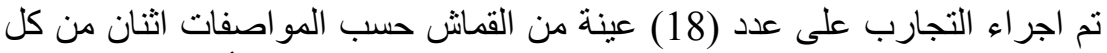
نوع قماش و قد نم إجر اء المعالجات الرطبة (الغليان - التبييض) للأقمشة المنتجة كما هو متبع بالشركة. ثانياً :الصبغات الطبيعية محل الدراسة:

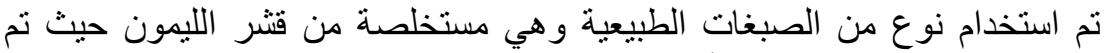

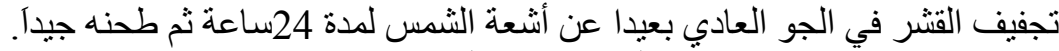
ثالثا:المادة المساعدة المستخدمة في الصباغة: 


\section{مجلة الاقتصاد المنزلي - مجلد 28 - العدد الرابع 2018}

تم استخدام مادة كبريتات الألومنيوم "الثباه"كمثبت للصبغة على القماش بنسبة (5)جم

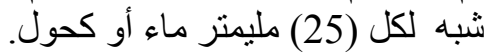

يتم نقع كمية من مسحوق قشر الليمون بنسبة (30جم من مسحوق قشر الليمون/ 250

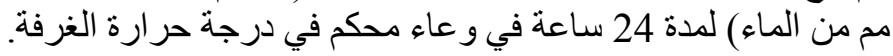

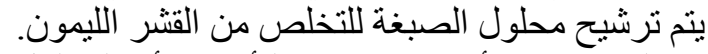

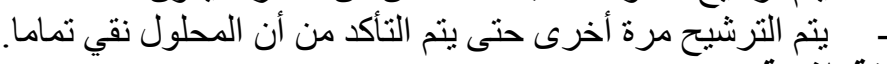

يتم نقع كمية من مسحوق قشر الليمون بنسبة (30جم من مسحوق قشر الليمون/ 250

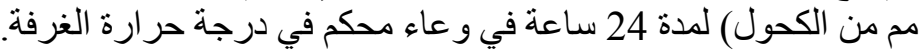

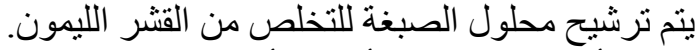

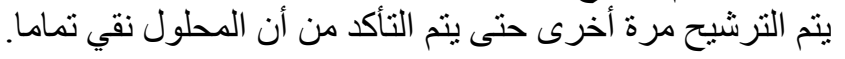

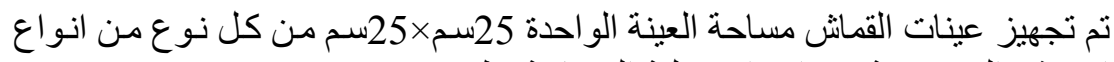

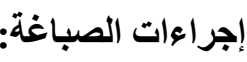

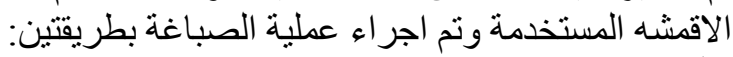

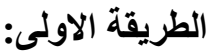

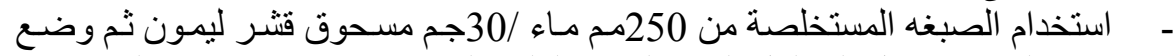
عينة القماش بداخل المحلول المستخلص و الغليان لمدة 30 دقيقة ثم تجفف العينـة عند درجة حرارة 40 درجة مئوية.

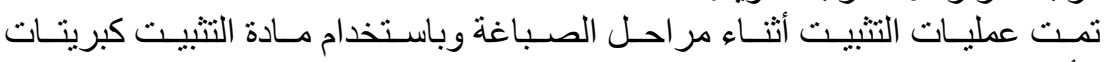
الألومنيوم (الثبة) (5جم من الثبه/ الثبة أثلاء 250 مم من الماء).

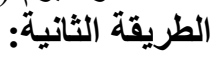

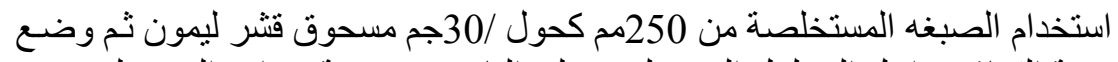

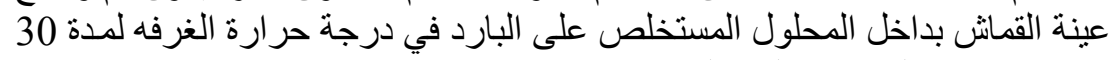
دقيقة ثم تجفة العينة في الجو العادي.

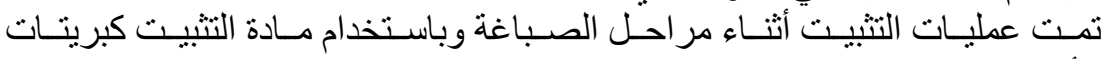

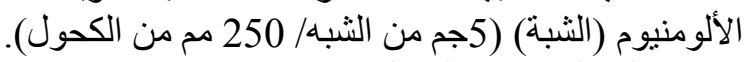

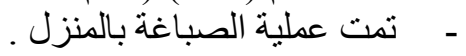
الاختبار ات المعمليه: إجر اء الاختبارات المعملية ( عمق اللون- الغسيلــ العرق- الاحتكالك ـ قوة الثد و الاستطالة للأقمشة ). تمت عملية الاختبار ات المعملية بمعامل المعهد القومي للمعايرة. 
مجلة الاقتصاد المنزلي - مجلد 28 ـ العدد الرابع 2018

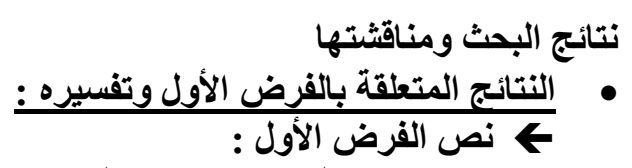

" توجد فروق ذات دلالة إحصائية بين العينات فى عمق العق اللون الر اجعـه إلى الاختلاف فى كلا

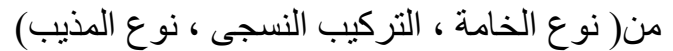

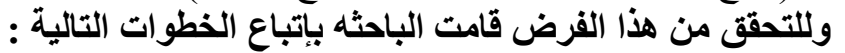

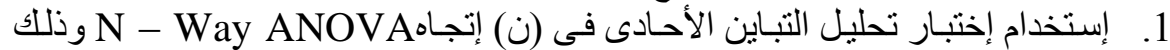

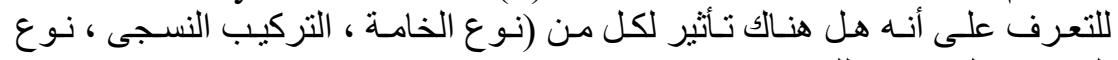

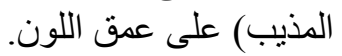

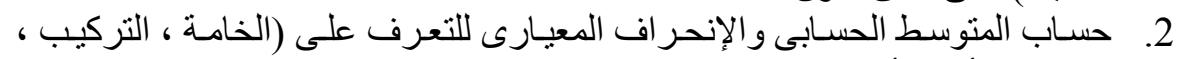

المذيب) الأكثر تأثير على عمق اللتى اللون.

جدول ( 1 ) يوضح الفروق بين العينات فى عمق اللى اللون اللون الراجعه إلى الاختلاف فى كلا من

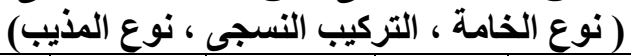

\begin{tabular}{|c|c|c|c|c|c|c|}
\hline مستوي الدلائ & الدلالة & $\mathbf{F}$ & المربعات & الرجية & المربعوع & المتغيرات \\
\hline $\begin{array}{l}\text { دالة عند } \\
\text { (0.05) }\end{array}$ & 0.0188 & 4.2399 & 0.1026 & 3 & 0.3078 & النسجيب \\
\hline غير دالة عند & 0.4513 & 0.8299 & 0.0201 & 2 & 0.0402 & نوع الخامة \\
\hline $\begin{array}{l}\text { دالة عند } \\
\text { (0.05) }\end{array}$ & 0.0120 & 5.6385 & 0.1364 & 2 & 0.2729 & نوع المذيب \\
\hline \multicolumn{3}{|c|}{ - } & 0.0242 & 19 & 0.4598 & الخطأ \\
\hline \multicolumn{3}{|c|}{-} & - & 27 & 1.5802 & المجموع \\
\hline
\end{tabular}

جدول (2) يوضح المتوسط الحسابى والانحر اف المعيارى لكل من نوع الخامة والتركيب

\begin{tabular}{|c|c|c|c|c|}
\hline الترتيب & الإنحر افالمعيارى & المتوسط الحسابى & \multicolumn{2}{|c|}{ المتغيرات } \\
\hline 3 & 0.0586 & 0.0744 & هينيكوم & \multirow{4}{*}{ النسجي } \\
\hline 4 & 0.446 & 0.0533 & كريب & \\
\hline 2 & 0.227 & 0.126 & شبيكة تقليدية & \\
\hline 1 & 0.402 & 0.447 & كريب لحمه & \\
\hline 1 & 0.279 & 0.197 & فيسكوز & \multirow{3}{*}{ الخامة } \\
\hline 2 & 0.226 & 0.137 & قطن مسرح & \\
\hline 3 & 0.0401 & 0.0511 & فبران & \\
\hline 3 & 0 & 0 & بدون & \multirow{3}{*}{ المذيب } \\
\hline 1 & 0.288 & 0.246 & كحول & \\
\hline 2 & 0.159 & 0.139 & ماء & \\
\hline
\end{tabular}




\section{مجلة الاقتصاد المنزلي - مجلد 28 - العدد الرابع 2018}

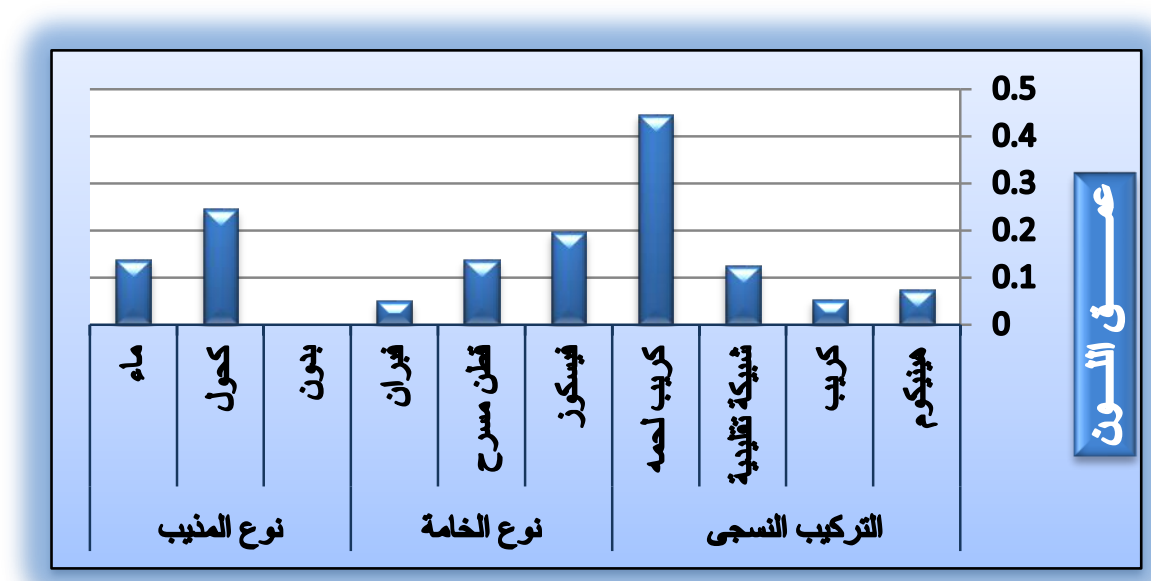

شكل (1) يوضح المتوسط الحسابى لكل من نوع الخامة والتركيب النسجى ونوع المذيب بالنسبة لعمث اللون التون

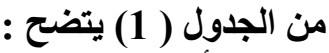

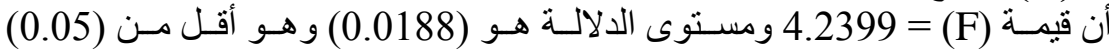

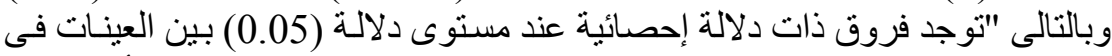

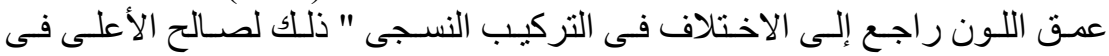

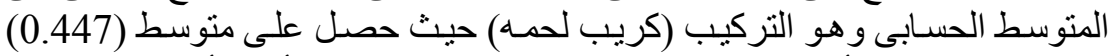

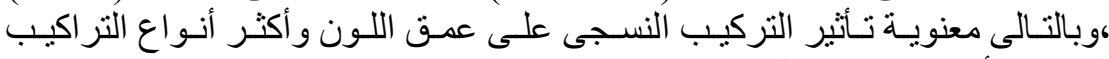
النسجية تأثير هو كريب اللحمده.

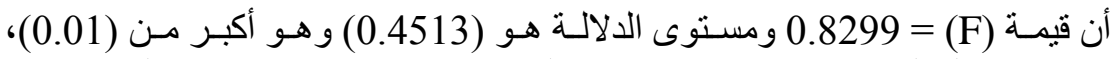

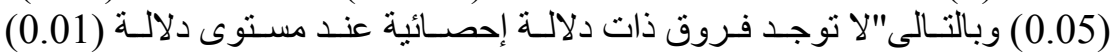

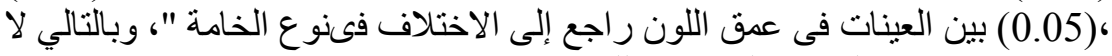

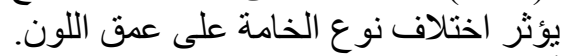

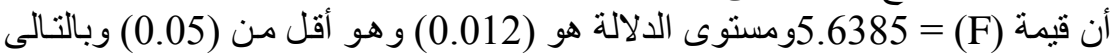

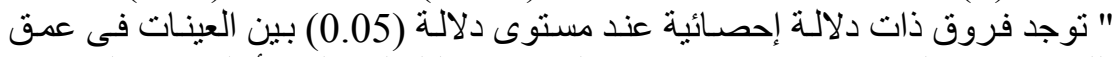

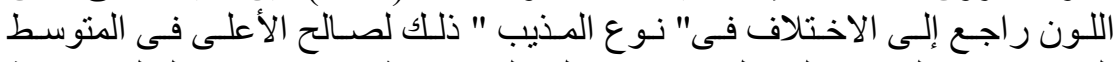

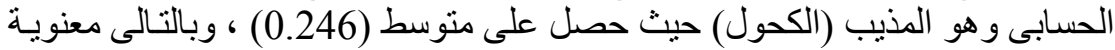
تأثثير نوع المذيب على عمق اللون وأكثر أنو اع المذيبات تأثنير هى الكحول.

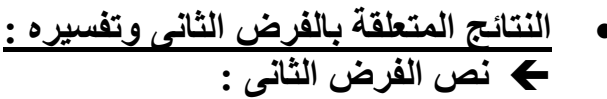

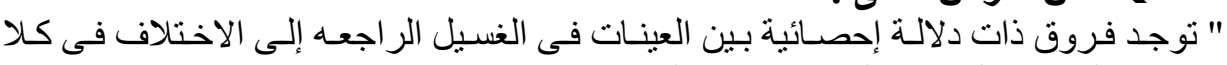

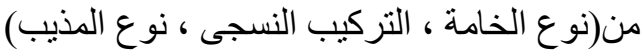


مجلة الاقتصاد المنزلي - مجلد 28 - العدد الرابع 2018

وللتحقق من هذا الفرض قامت الباحثه بإتباع الخطوات التالية :

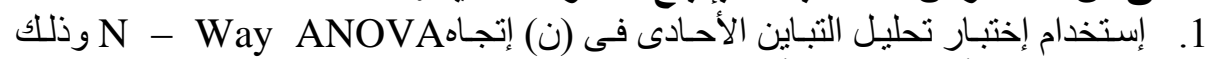

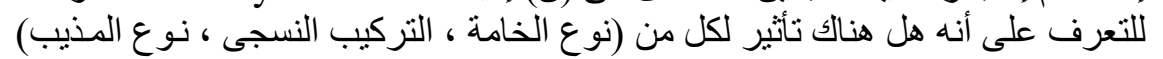
على الغسيل.

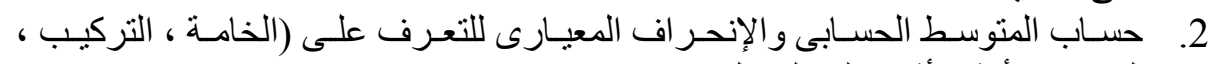
المذيب) الأكثر تأثير على الغير الغسيل. جلول (3 ) يوضح الفروق بين العينات فى الغسيل الراجعه إلى الاختلاف فى كلا من الغن الغيل

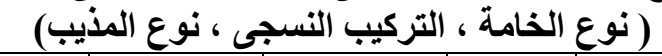

\begin{tabular}{|c|c|c|c|c|c|c|}
\hline & & & & & & \\
\hline مستوى الدلالة & الالالة & $\mathbf{F}$ & المربعات & الحرية & المربعوات & المتغيرات \\
\hline غير دالة عند & 0.867 & 0.241 & 0.0370 & 3 & 0.1111 & الترجيب \\
\hline غير دالة عند & 0.836 & 0.180 & 0.0278 & 2 & 0.0556 & نوع الخامة \\
\hline $\begin{array}{l}\text { دالة عند } \\
\text { (0.01) }\end{array}$ & 0.000 & 96.203 & 14.8148 & 2 & 29.6296 & نوع المذيب \\
\hline \multicolumn{3}{|c|}{ - } & 0.1540 & 19 & 2.9259 & الخطأ \\
\hline \multicolumn{3}{|c|}{-} & - & 27 & 92.00 & المجموع \\
\hline
\end{tabular}

جلول (4) يوضح المتوسط الحسابى والانحراف المعيارى لكل من نوع الخامة والتركيب النسجى ونوع المذيب بالنسبة للفسيل

\begin{tabular}{|c|c|c|c|c|}
\hline الترتيب & الإنحراف المعيارى & المتوسط الحسابى & \multicolumn{2}{|c|}{ المتغيرات } \\
\hline 1 & 1.236 & 1.556 & هينيكوم & \multirow{4}{*}{ النسجيب } \\
\hline 2 & 1.225 & 1.500 & كريب & \\
\hline 3 & 1.130 & 1.444 & شبيكة تقليدية & \\
\hline 4 & 1.155 & 1.333 & كريب لحمه & \\
\hline 2 & 1.130 & 1.444 & فيسكوز & \multirow{3}{*}{ الخامعة } \\
\hline 1 & 1.236 & 1.556 & قطن مسرح & \\
\hline 2 & 1.130 & 1.444 & فبران & \\
\hline 2 & 0 & 0 & بلون & \multirow{3}{*}{ المذيب } \\
\hline 1 & 0.441 & 2.222 & كحول & \\
\hline 1 & 0.441 & 2.222 & ماء & \\
\hline
\end{tabular}




\section{مجلة الاقتصاد المنزلي - مجلد 28 - العدد الرابع 2018}

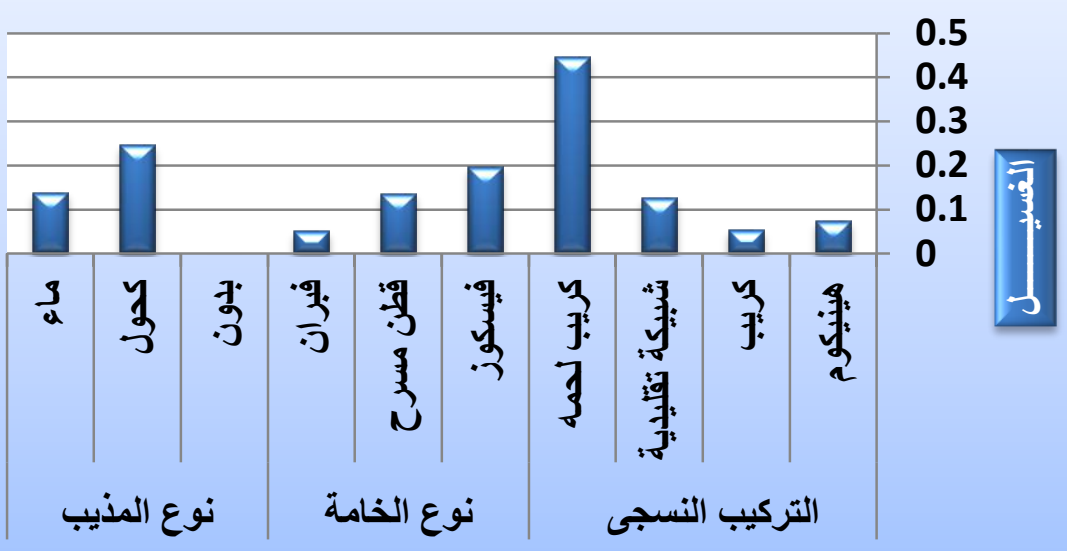

شكل (2) يوضح المتوسط الحسابى لكل من نوع الخامة والتركيب النسجى ونوع المذيب بالنسبة للغنيل فئ

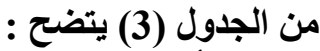

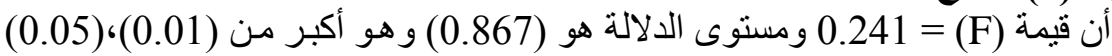

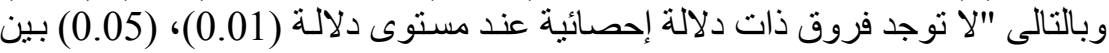

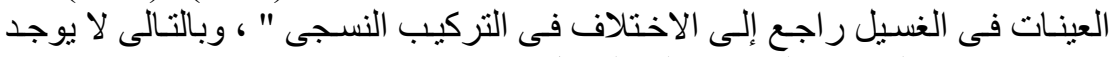
ناثير لاختلاف التركيب النسجى على الغئ الغسيل.

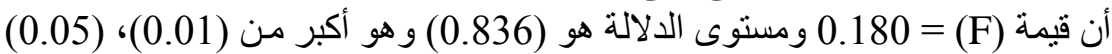

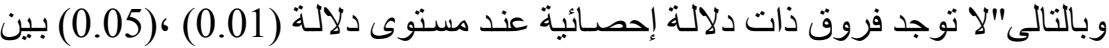

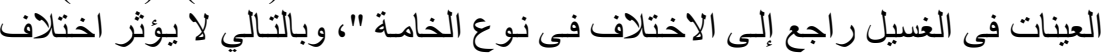

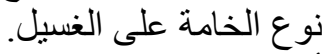

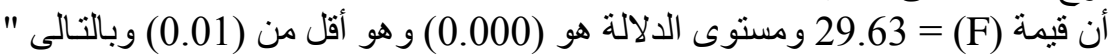

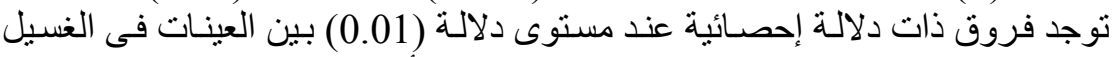

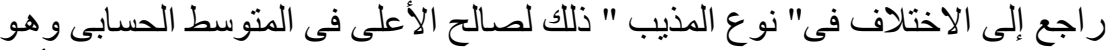

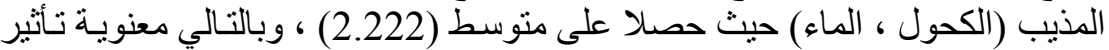
نوع المذيب على الغسيل وأن الكحول و الماء لهما نفس التأثير.

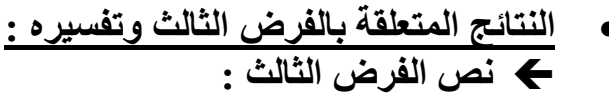

" توجد فروق ذات دلالة إحصائية بين العينات فى العرق القوق القلوى الر اجعه إلى الاختلاف فى كلا

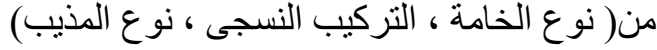


مجلة الاقتصاد المنزلي - مجلد 28 - العدد الرابع 2018

وللتحقق من هذا الفرض قامت الباحثه بإتباع الخطوات التالية :

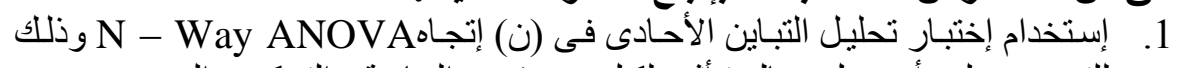

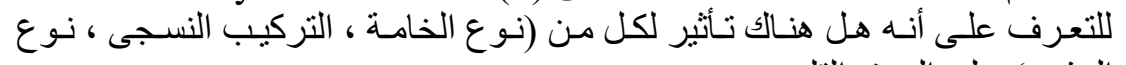

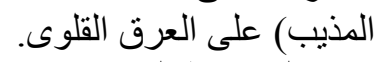

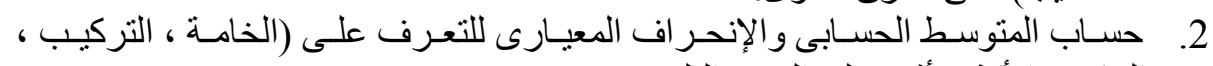

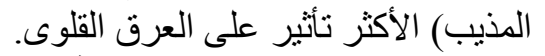

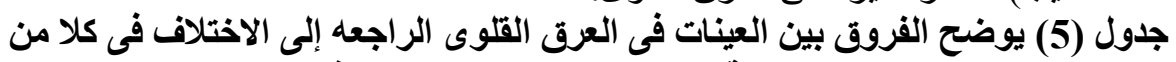

\begin{tabular}{|c|c|c|c|c|c|c|}
\hline مستوى الدلالة & الدلالة & $\mathbf{F}$ & المربعات & الحرية & المربعات & المتغيرات \\
\hline غير دالة عند & 0.877 & 0.226 & 0.0741 & 3 & 0.222 & النسجيب \\
\hline غير دالة عند & 0.226 & 1.612 & 0.5278 & 2 & 1.056 & نوع الخامة \\
\hline $\begin{array}{l}\text { دالة عند) } \\
\text { (0.01) }\end{array}$ & 0.000 & 104.84 & 34.3333 & 2 & 68.667 & نوع المذيب \\
\hline \multicolumn{3}{|c|}{ - } & 0.3275 & 19 & 6.222 & الخطأ \\
\hline \multicolumn{3}{|c|}{-} & - & 27 & 210.0 & المجموع \\
\hline
\end{tabular}

جدول (6) يوضح المتوسط الحسابى والاتحر اف المعيارى لكل من نوع الخامة والتركيب النسجى ونوع المذيب بالنسبة للعرق القلوى العن

\begin{tabular}{|c|c|c|c|c|}
\hline الترتيب & الإنحراف المعيارى & المتوسط الحسابى & \multicolumn{2}{|c|}{ المتغيرات } \\
\hline 2 & 1.787 & 2.222 & هينيكوم & \multirow{4}{*}{ النسجى } \\
\hline 1 & 1.975 & 2.500 & كريب & \\
\hline 3 & 1.691 & 2.111 & شبيكة تقليدية & \\
\hline 4 & 2 & 2 & كريب لحمه & \\
\hline 3 & 1.537 & 1.889 & فيسكوز & \multirow{3}{*}{ الخامة } \\
\hline 1 & 1.878 & 2.444 & قطن مسرح & \\
\hline 2 & 1.871 & 2.333 & فبران & \\
\hline 3 & 0 & 0 & بدون & \multirow{3}{*}{ المذيب } \\
\hline 1 & 0.500 & 3.667 & كحول & \\
\hline 2 & 0.866 & 3 & ماء & \\
\hline
\end{tabular}




\section{مجلة الاقتصاد المنزلي - مجلد 28 - العدد الرابع 2018}

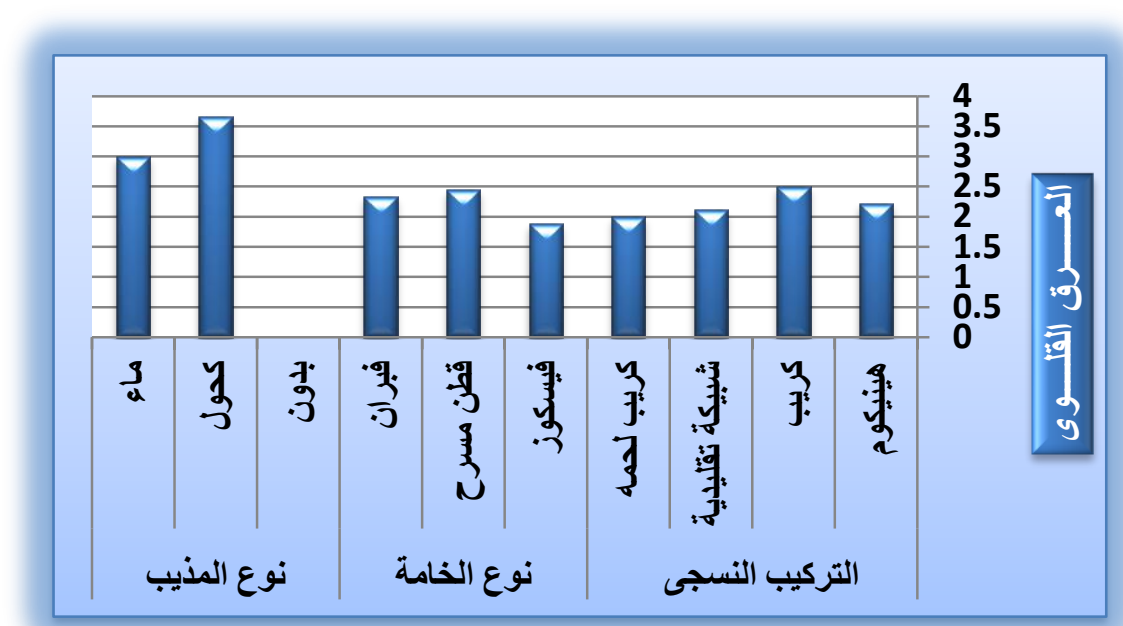

شكل (3) يوضح المتوسط الحسابى لكل من نوع الخامة والتركيب النسجى ونوع المذيب

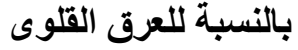

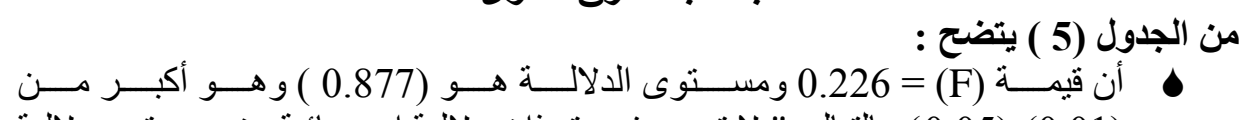

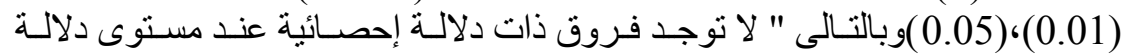

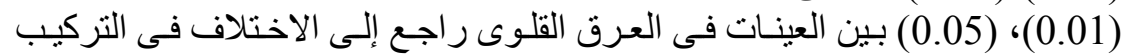

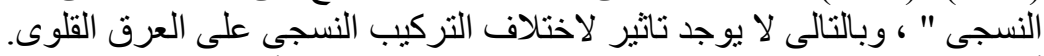

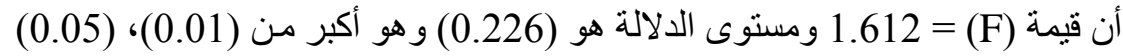

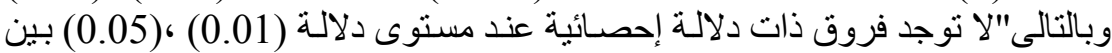

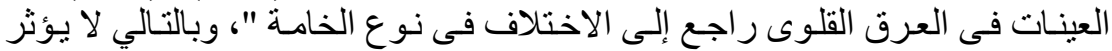

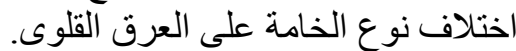

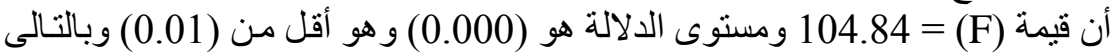

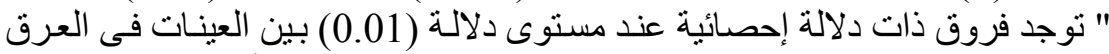

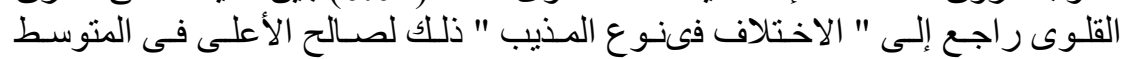

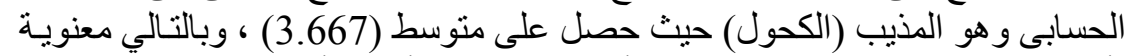
تأثثير نوع المذيب على العرق القلوى وأن أن الكحول هو الأعلى تأثنير.

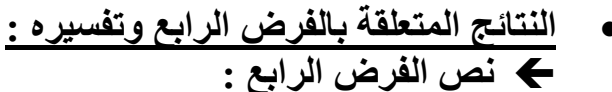

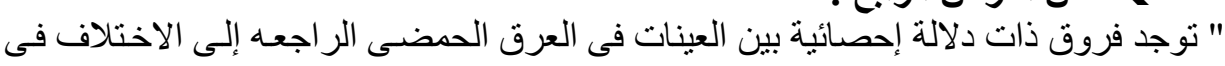
كلا من (نوع الخامة ، التركيب النسجى ، نو نوع العينات المذيب). 
مجلة الاقتصاد المنزلي - مجلد 28 - العدد الرابع 2018

وللتحقق من هذا الفرض قامت الباحثه بإتباع الخطوات التالية :

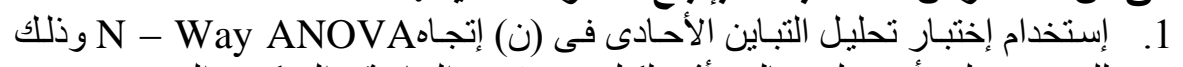

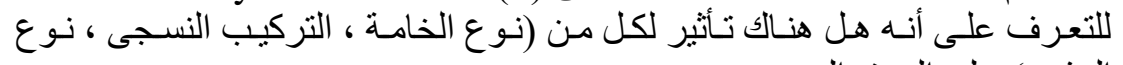

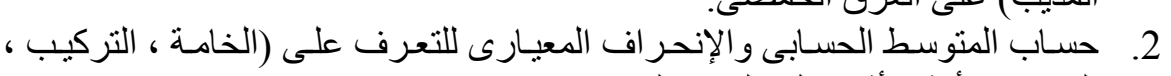
المذيب) الأكثر تأثير على العرق الحمضئ.

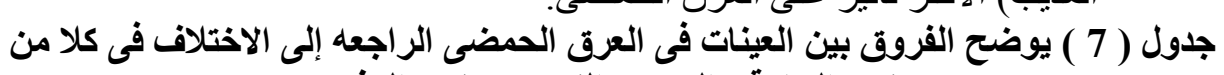

\begin{tabular}{|c|c|c|c|c|c|c|}
\hline مستوى الدلالة & الدلالة & $\mathbf{F}$ & المربعات & الرجرية & المربعوع & المتغيرات \\
\hline غير دالة عند & 0.945 & 0.124 & 0.074 & 3 & 0.222 & النسجيب \\
\hline $\begin{array}{c}\text { غير دالة عند) } \\
\text { (0.05) }\end{array}$ & 0.429 & 0.885 & 0.528 & 2 & 1.056 & نوع الخامة \\
\hline $\begin{array}{l}\text { دالة عند } \\
\text { (0.01) }\end{array}$ & 0.000 & 46.010 & 27.444 & 2 & 54.889 & نوع المذيب \\
\hline \multicolumn{3}{|c|}{-} & 0.596 & 19 & 11.333 & الخطأ \\
\hline \multicolumn{3}{|c|}{-} & - & 27 & 176.000 & المجموع \\
\hline
\end{tabular}

جلول (8) يوضح المتوسط الحسابى والانحراف المعيارى لكل من نوع الخامة والتركيب

\begin{tabular}{|c|c|c|c|c|}
\hline الترتيب & المعيارى & المتوسط الحسابى & \multicolumn{2}{|c|}{ المتغيرات } \\
\hline 3 & 1.76 & 1.89 & هينيكوم & \multirow{4}{*}{ النسجى } \\
\hline 1 & 1.72 & 2.17 & كريب & \\
\hline 2 & 1.69 & 2.11 & شبيكة تقليدية & \\
\hline 4 & 1.53 & 1.67 & كريب لحمه & \\
\hline 3 & 1.50 & 1.67 & فيسكوز & \multirow{3}{*}{ الخامة } \\
\hline 2 & 1.62 & 2.11 & قطن مسرح & \\
\hline 1 & 1.86 & 2.22 & فبران & \\
\hline 3 & $\mathbf{0}$ & $\mathbf{0}$ & بدون & \multirow{3}{*}{ المذيب } \\
\hline 1 & 0.83 & 3.22 & كحول & \\
\hline 2 & 0.98 & 2.78 & ماء & \\
\hline
\end{tabular}




\section{مجلة الاقتصاد المنزلي - مجلد 28 ـ العدد الرابع 2018}

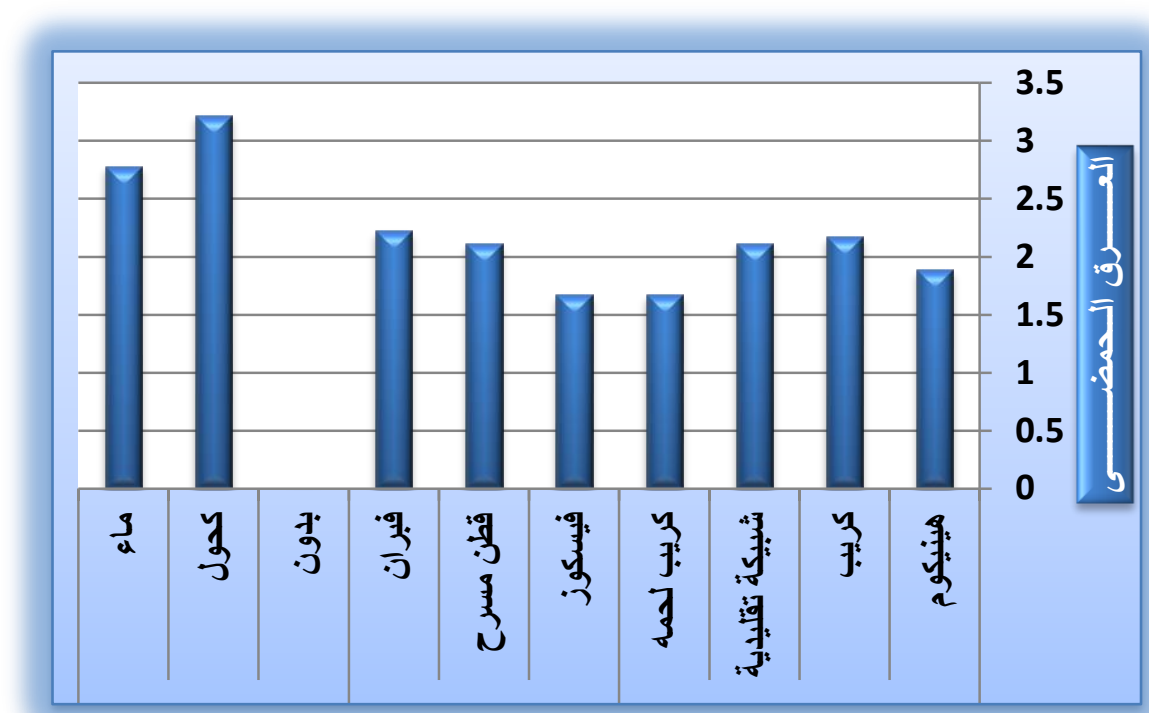

شكل ( 4) يوضح المتوسط الحسابى لكل من نوع الخامة والتركيب النسجى ونوع المذيب

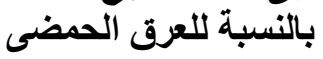

من الجدول ( 7 ) يتضح :

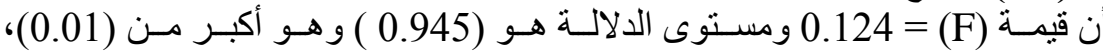

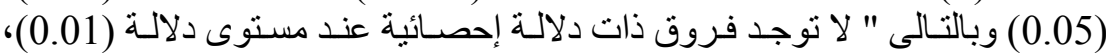

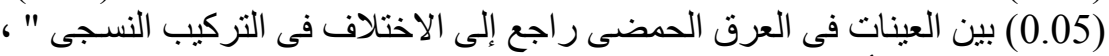

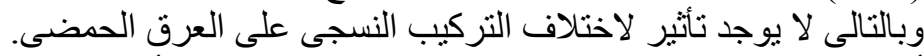

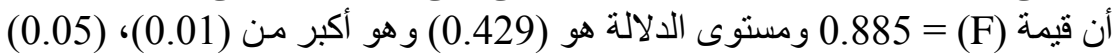

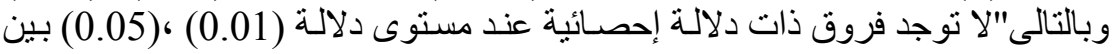

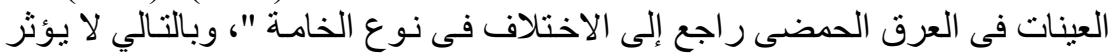

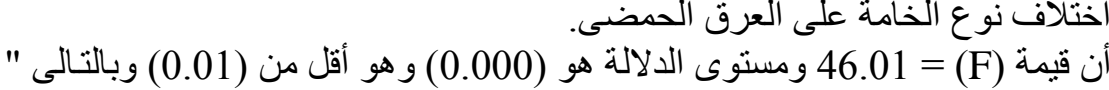

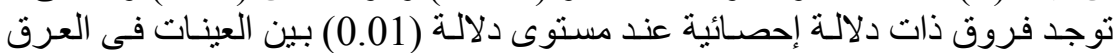

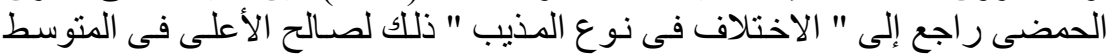

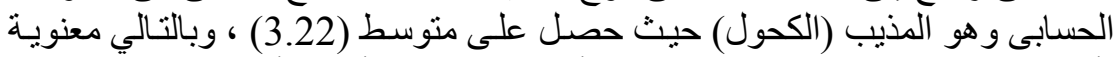
تأثير نوع المذيب على العرق الحمضى ولى أن الكحول هو الأعلى تأثير.

\section{• النتائج المتعلقة بالفرض الخامس وتفسيره :

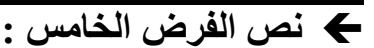

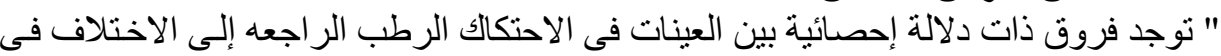

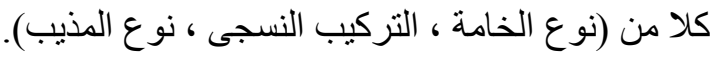


مجلة الاقتصاد المنزلي - مجلد 28 - العدد الرابع 2018

وللتحقق من هذا الفرض قامت الباحثه بإتباع الخطوات التالية :

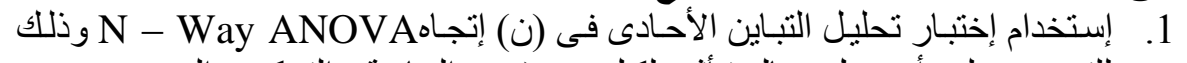

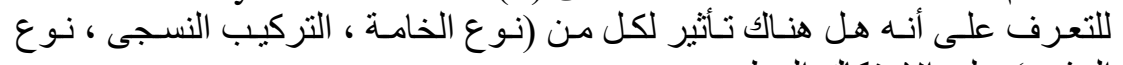

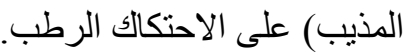

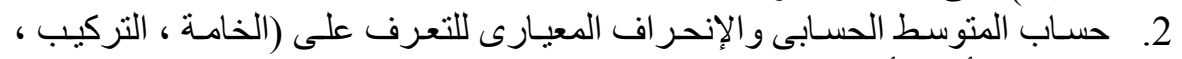

المذيب) الأكثر نأثنير على الاحتكالك الرطف.

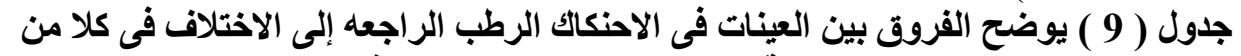

\begin{tabular}{|c|c|c|c|c|c|c|}
\hline مستوى الدلاكة & الدلالة & $\mathbf{F}$ & المربعات & الحرية & المربعوات & المتغيرات \\
\hline \multirow{3}{*}{ لالاتوجد } & - & - & 0.000 & 3 & 0.000 & التركيب النسجى \\
\hline & - & - & 0.000 & 2 & 0.000 & نوع الخامة \\
\hline & - & - & 75.000 & 2 & 150.000 & نوع المذيب \\
\hline \multicolumn{3}{|c|}{-} & 0.000 & 19 & 0.000 & الخطأ \\
\hline & - & & & 27 & 450.000 & المجموع \\
\hline
\end{tabular}

جدول (10) يوضح المتوسط الحسابى والانحراف المعيارى لكل من نوع الخامة والتركيب النسجى ونوع المذيب بالنسبة للاحتكاك الرطب الريب

\begin{tabular}{|c|c|c|c|c|}
\hline الترتيب & الإنحيارى & المتوسط الحسابى & \multicolumn{2}{|c|}{ المتغيرات } \\
\hline \multirow{4}{*}{ نفس الترتيب } & 2.50 & 3.333 & هينيكوم & \multirow{4}{*}{ النسجى } \\
\hline & 2.50 & 3.333 & كريب & \\
\hline & 2.50 & 3.333 & شبيكة تقليدية & \\
\hline & 2.50 & 3.333 & كريب لحمه & \\
\hline \multirow{3}{*}{ نفس الترتيب } & 2.50 & 3.333 & فيسكوز & \multirow{3}{*}{ الخامة } \\
\hline & 2.50 & 3.333 & قطن مسرح & \\
\hline & 2.50 & 3.333 & فبران & \\
\hline \multirow{3}{*}{ نفس الترتيب } & $\mathbf{0}$ & 0 & بدون & \multirow{3}{*}{ المذيب } \\
\hline & $\mathbf{0}$ & 5 & كحول & \\
\hline & $\mathbf{0}$ & 5 & ماء & \\
\hline
\end{tabular}


مجلة الاقتصاد المنزلي - مجلد 28 - العدد الرابع 2018

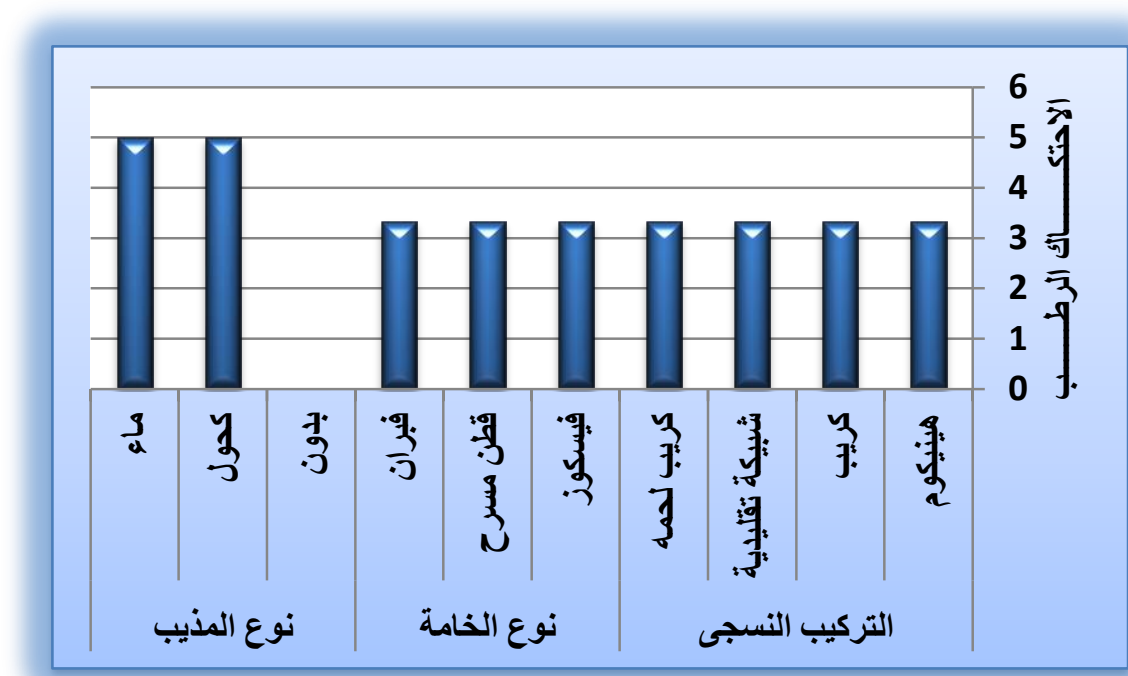

شكل (5) يوضح المتوسط الحسابى لكل من نوع الخامة والتركيب النسجى ونوع المذيب بالنسبة للاحتكاك الرطب التب من الجدول (9) يتضح :

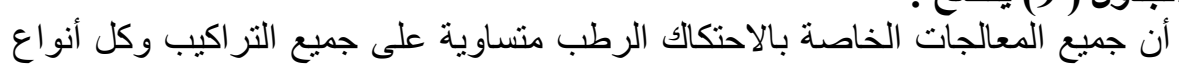
الخامات وجميع المذيبات وبالتالى لا توجد دلالة الأكاك الرطائية .

\section{•}

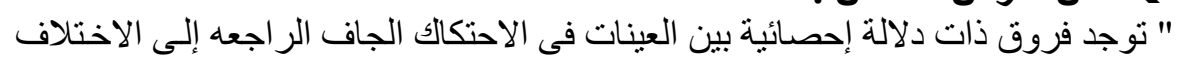

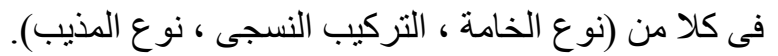

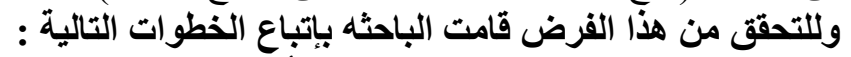

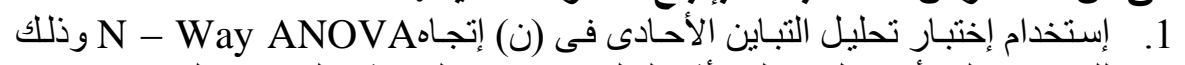

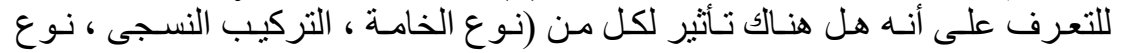

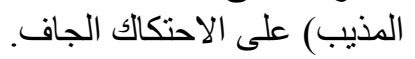

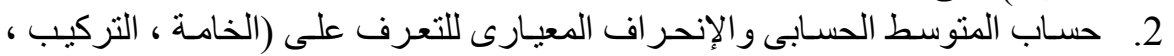
المذيب) الأكثر تأثثر على الاحتكالك الجاف. 
مجلة الاقتصاد المنزلي - مجلد 28 - العدد الرابع 2018

جدول (11) يوضح الفروق بين العينات فى الاحنكاك الجاف الراجعه إلى الاختلاف فى كلا من

\begin{tabular}{|c|c|c|c|c|c|c|c|}
\hline 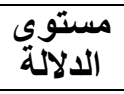 & & $\mathbf{F}$ & المتوبعات & 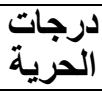 & المجبعات & \multicolumn{2}{|c|}{ المتغير ات } \\
\hline \multirow{3}{*}{ ل الالوجذ } & & - & 0.000 & 3 & 0.000 & \multicolumn{2}{|c|}{ النتركيب } \\
\hline & & - & 0.000 & 2 & $\mathbf{0 . 0 0 0}$ & \multicolumn{2}{|c|}{ نوع الخامة } \\
\hline & & - & 75.000 & 2 & 150.000 & \multicolumn{2}{|c|}{ نوع المذيب } \\
\hline \multicolumn{3}{|c|}{-} & 0.000 & 19 & 0.000 & \multicolumn{2}{|c|}{ آلخطا } \\
\hline \multicolumn{3}{|c|}{-} & & 27 & 450.000 & \multicolumn{2}{|c|}{ المجموع } \\
\hline \multicolumn{8}{|c|}{ 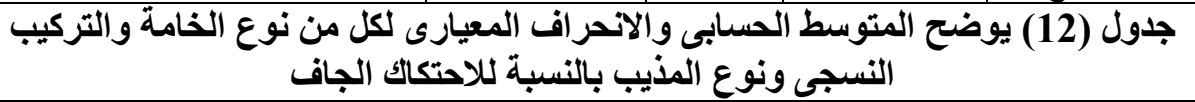 } \\
\hline \multicolumn{2}{|c|}{ الترتيب } & 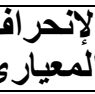 & سابى سط & & \multicolumn{3}{|c|}{ المتغيرات } \\
\hline \multirow{4}{*}{\multicolumn{2}{|c|}{ نفس الترتيب }} & 2.89 & 3.3 & & هينيكوم & & \multirow{4}{*}{ 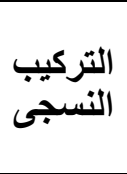 } \\
\hline & & 2.50 & 3.3 & & كريب & & \\
\hline & & 2.50 & 3.3 & & يكة تقليدية & & \\
\hline & & 2.50 & 3.3 & & ريب لحمه & & \\
\hline \multirow{3}{*}{\multicolumn{2}{|c|}{ نفس الترتيب }} & 2.50 & 3.3 & & فَيسكوز & & \multirow{3}{*}{ الخامعة } \\
\hline & & 2.50 & 3.3 & & طن مسرح & & \\
\hline & & 2.50 & 3.3 & & فَبران & & \\
\hline \multirow{3}{*}{\multicolumn{2}{|c|}{ نفس الترتيب }} & $\mathbf{0}$ & ( & & بلدون & & \multirow{3}{*}{ 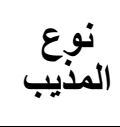 } \\
\hline & & $\mathbf{0}$ & 5 & & كحول & & \\
\hline & & $\mathbf{0}$ & 5 & & ماء & & \\
\hline
\end{tabular}

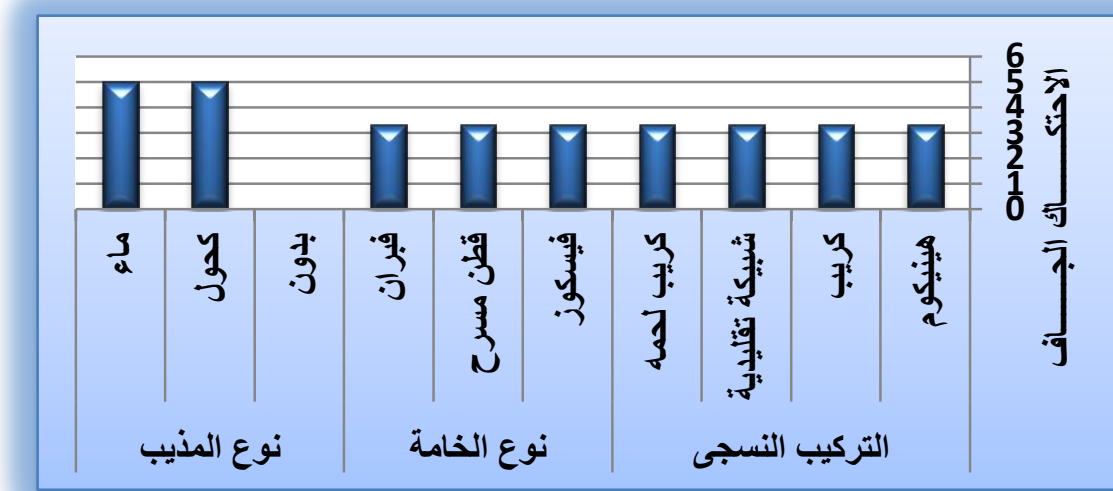

شكل ( 6) يوضح المتوسط الحسابى لكل من نوع الخامة والتركيب النسجى ونوع المذيب

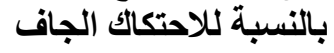


مجلة الاقتصاد المنزلي - مجلا 28 - العدد الرابع 2018

أن جميع المعالجات الخاصنة بالاحتكاك الجاف متساوية على جميع التر اكيب النسجية وكل أنواع 11 ) يتضاع

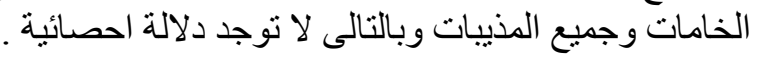

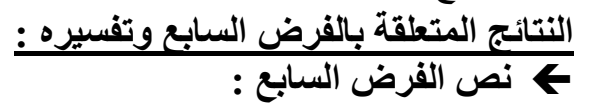

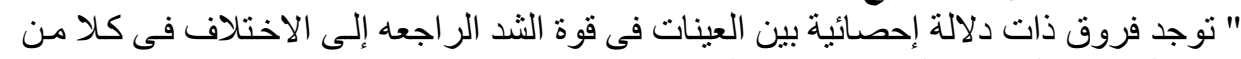

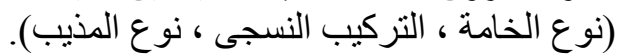

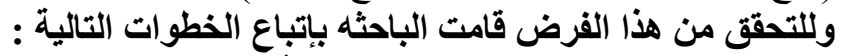

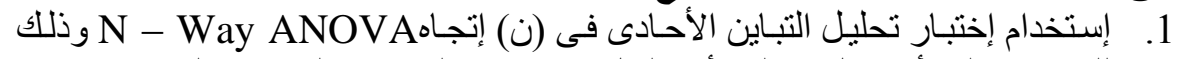

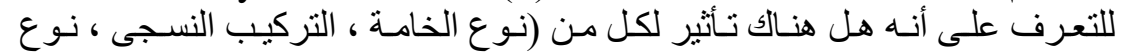
المذيب) على قوة الثند.

2. حسـاب المتوسط الحسبابى و الإنحر اف المعيـارى للتعرف على على (الخامـة ، التركيب ، المذيب) الأكثر تأثير على قوة الثند. جلول ( 13 ) يوضح الفروق بين العينات في قوة الثد الثرة الراجعه إلى الاختلاف فى كلا من

\begin{tabular}{|c|c|c|c|c|c|c|}
\hline مستوى الدلالة & الدلالة & $\mathbf{F}$ & المربعات & الرجرية & المربعوت & المتغيرات \\
\hline $\begin{array}{c}\text { غير دالة عند } \\
\text { (0.05) }\end{array}$ & 0.485 & 0.846 & 11711.887 & 3 & 35135.66 & التركيب \\
\hline $\begin{array}{l}\text { دالة عند } \\
\text { (0.05) }\end{array}$ & 0.039 & 3.861 & 53421.339 & 2 & 106842.68 & نوع الخامة \\
\hline $\begin{array}{l}\text { دالة عند } \\
\text { (0.05) }\end{array}$ & 0.035 & 4.005 & 55414.330 & 2 & 110828.66 & نوع المذيب \\
\hline \multirow{2}{*}{\multicolumn{3}{|c|}{-}} & 13836.529 & 19 & 262894.06 & الخطأ \\
\hline & & & - & 27 & 5479731.6 & المجموع \\
\hline
\end{tabular}

\begin{tabular}{|c|c|c|c|c|}
\hline الترتيب & الإنحراف المعيارى & المتوسط الحسابى & ت تغيرات & \\
\hline 3 & 138.57 & 409.47 & 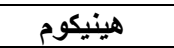 & \multirow{4}{*}{ النسجى } \\
\hline 1 & 60.88 & 510.82 & كريب & \\
\hline 4 & 180.77 & 397.30 & شبيكة تقليدية & \\
\hline 2 & 153.29 & 409.87 & كريب لحمه & \\
\hline 3 & 159.73 & 344.32 & فيسكوز & \multirow{3}{*}{ الخامة } \\
\hline 1 & 72.96 & 511.27 & قطن مسرح & \\
\hline 2 & 142.37 & 428.34 & فبران & \\
\hline 1 & 140.28 & 514.211 & بدون & \multirow{3}{*}{ الدذيب } \\
\hline 2 & 128.50 & 408.94 & كحول & \\
\hline 3 & 129.39 & 360.78 & ماء & \\
\hline
\end{tabular}




\section{مجلة الاقتصاد المنزلي - مجلد 28 ـ العدد الرابع 2018}

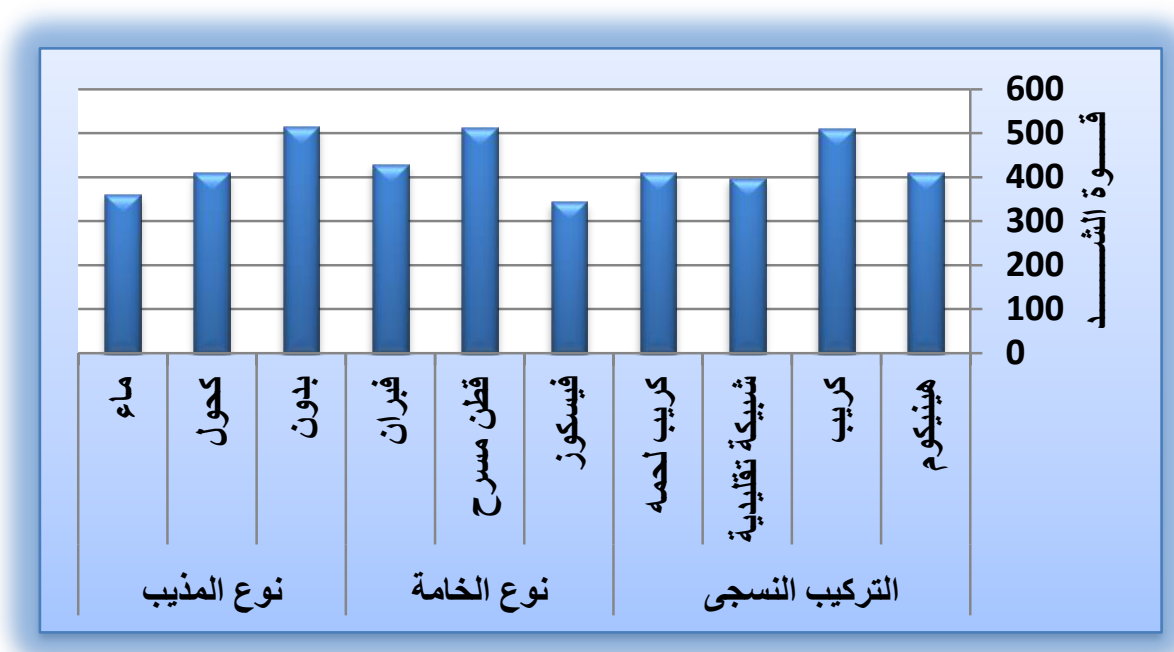

شكل ( 7) يوضح المتوسط الحسابى لكل من نوع الخامة والتركيب النسجى ونوع المذيب بالنسبة بقوة الثد الثن

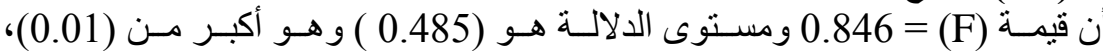

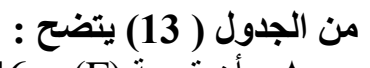

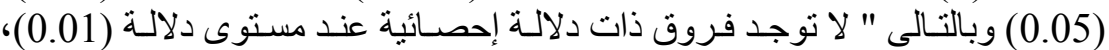

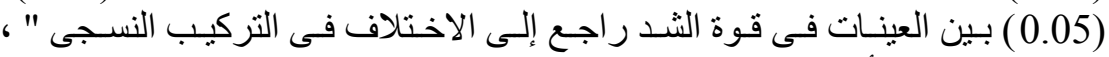

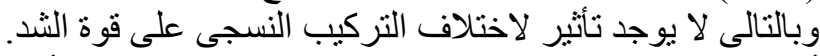

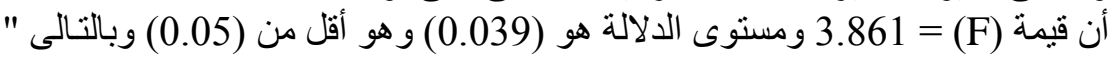

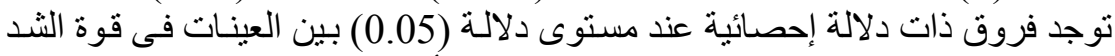

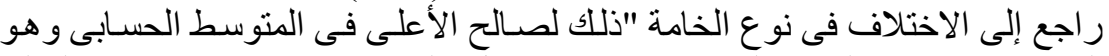

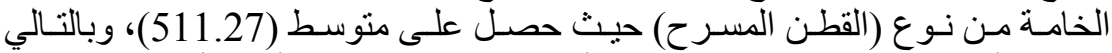

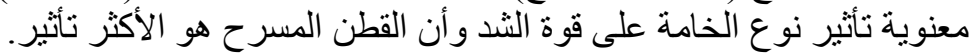

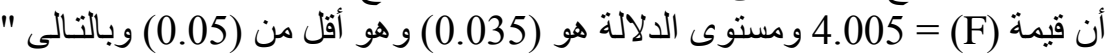

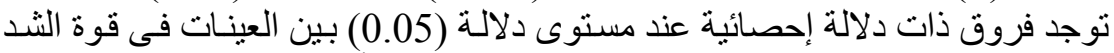

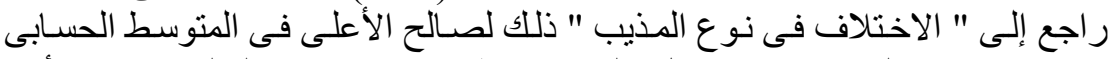

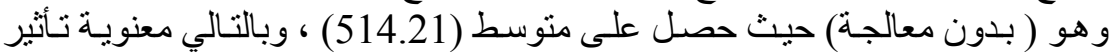

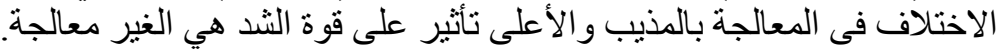
• " توجد فروق ذات دلالة إحصائية بين العينات فى الاستطالة الر اجعه إلى الاختلاف فى كلا من

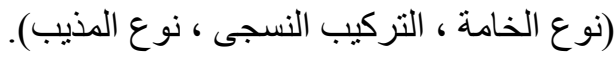


مجلة الاقتصاد المنزلي - مجلد 28 - العدد الرابع 2018

وللتحقق من هذا الفرض قامتالباحثه بإتباع الخطوات التالية :

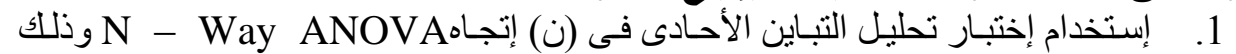

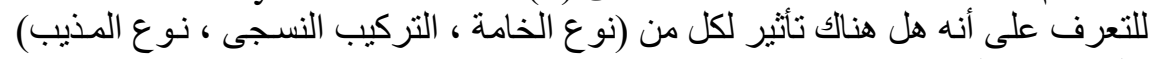
على الاستطالة.

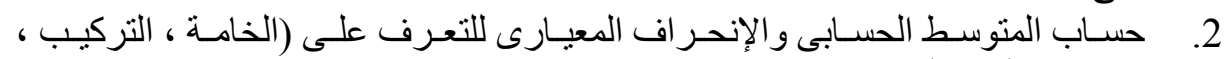
المذيب) الأكثر تأثير على الاستطالة.

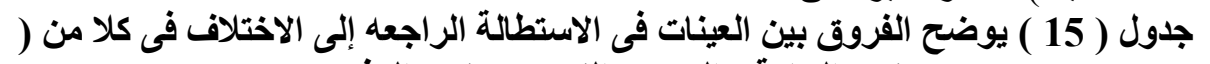

\begin{tabular}{|c|c|c|c|c|c|c|}
\hline مستولة الدلالة & الدلالة & $\mathbf{F}$ & المربعات & الدرجية & المجبعوت & المتغيرات \\
\hline غير دالة عند & 0.192 & 1.742 & 34.299 & 3 & 102.898 & النسجيب \\
\hline غير دالة عند & 0.156 & 2.051 & 40.390 & 2 & 80.780 & نوع الخامة \\
\hline غير دالة عند & 0.384 & 1.008 & 19.841 & 2 & 39.681 & نوع المذيب \\
\hline \multicolumn{3}{|c|}{ - } & 19.691 & 19 & 374.132 & الخطأ \\
\hline \multicolumn{3}{|c|}{-} & - & 27 & 3888.103 & المجموع \\
\hline
\end{tabular}

جدول (16) يوضح المتوسط الحسابى والاتحراف المعيارى لكل من نوع الخامة والتركيب

\begin{tabular}{|c|c|c|c|c|}
\hline الترتيب & المعيارى الإنحراف & الحستابي & متغيرات & \\
\hline 1 & 3.62 & 11.56 & هينيكوم & \multirow{4}{*}{ النسجيب } \\
\hline 2 & 2.52 & 10.65 & كريب & \\
\hline 4 & 1.38 & 7.26 & شبيكة تقليدية & \\
\hline 3 & 0.696 & 7.74 & كريب لحمه & \\
\hline 1 & 6.50 & 12.48 & فيسكوز & \multirow{3}{*}{ الخامة } \\
\hline 3 & 2.23 & 10.30 & قطن مسرح & \\
\hline 2 & 4.17 & 10.62 & فبران & \\
\hline 3 & 6.44 & 9.42 & بدون & \multirow{3}{*}{ المذيب } \\
\hline 2 & 3.12 & 11.96 & كحول & \\
\hline 1 & 3.39 & 12.02 & ماء & \\
\hline
\end{tabular}




\section{مجلة الاقتصاد المنزلي - مجلد 28 - العدد الرابع 2018}

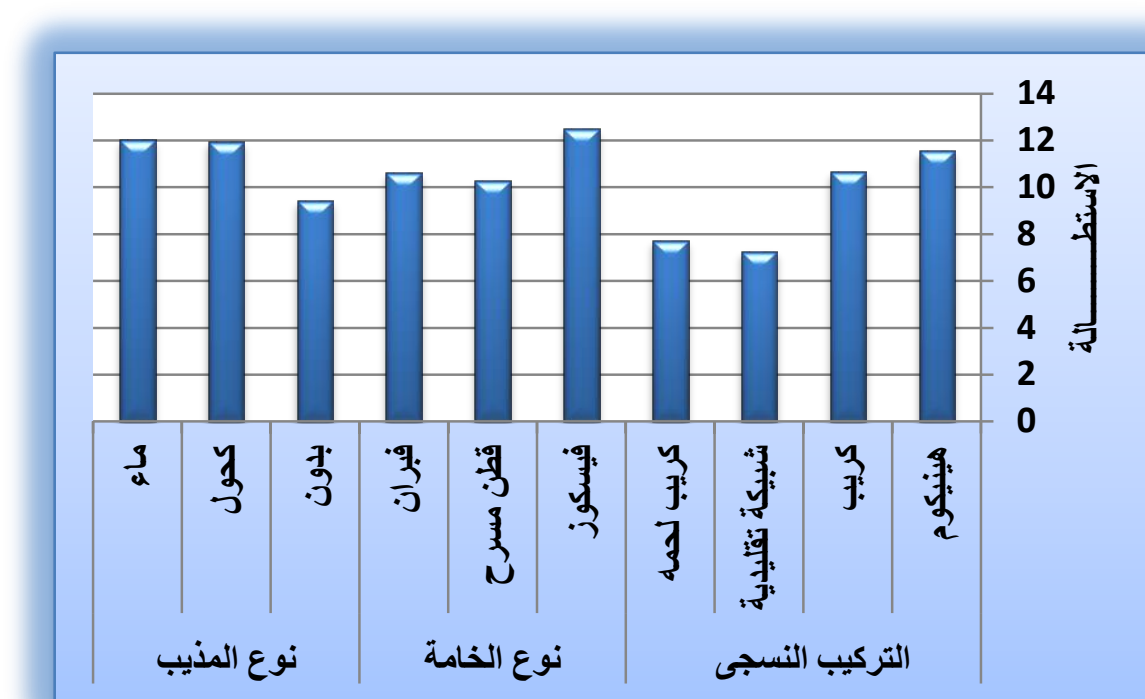

شكل (8 ) يوضح المتوسط الحسابى لكل من نوع الخامة والتركيب النسجى ونوع المذيب بالنسبة بالاسنطلة من نوعة

من الجدول ( 15 ) يتضح : (F)

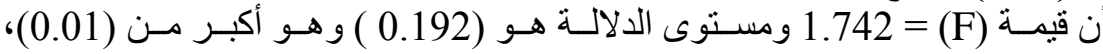

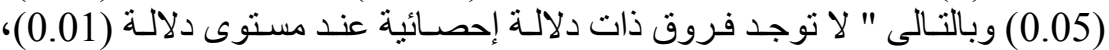

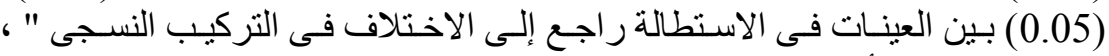

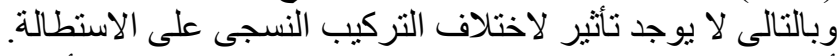

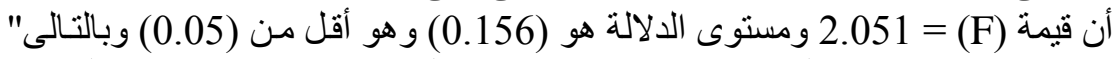

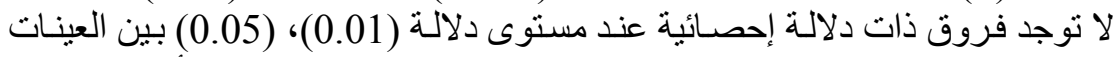

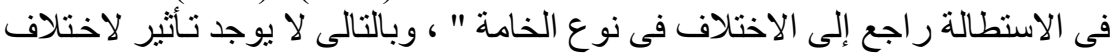

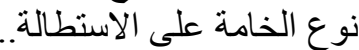

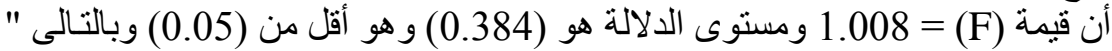

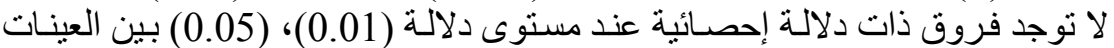

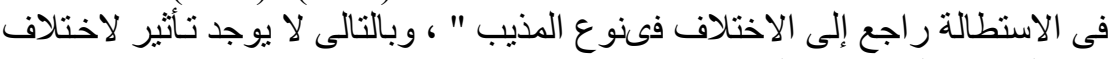
نوع المذيب على الاستطالة. 
مجلة الاقتصاد المنزلي - مجلد 28 - العدد الرابع 2018

جدول(17) يوضح معامل الجودة الكلية لكل عينة وترتيبها بالنسبة للمعالجات ككل

\begin{tabular}{|c|c|c|c|c|c|c|c|c|c|c|c|c|c|}
\hline 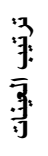 & $\frac{3}{3}$ & 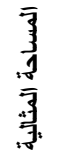 & $\begin{array}{l}\overline{3} \\
\text { 䍂 } \\
3\end{array}$ & 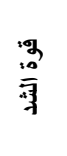 & 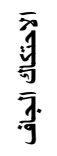 & $\begin{array}{l}\bar{y} \\
\text { 氛 } \\
\overline{3} \\
\text { 势. }\end{array}$ & $\begin{array}{l}\overline{3} \\
\overline{3} \\
\bar{y} \\
\cdot \bar{y}\end{array}$ & $\begin{array}{l}\overline{3} \\
\text { 宁 } \\
\text { 司, }\end{array}$ & 疍 & $\begin{array}{l}\text { 多 } \\
\text { 示 }\end{array}$ & $\frac{\sqrt[3]{3}}{\overline{3}}$ & $\begin{array}{l}3 \\
\frac{3}{3} \\
\frac{3}{3}\end{array}$ & $\begin{array}{l}\overline{3} \\
\text { 哥 } \\
\text { 事 }\end{array}$ \\
\hline 19 & 16 & 128 & 33.4 & 94.3 & 0 & 0 & 0 & 0 & 0 & 0 & بلدون & مسرح & \multirow{9}{*}{ 壶 } \\
\hline 8 & 71.2 & 570 & 44.6 & 79.1 & 100 & 100 & 60 & 100 & 66.7 & 19.2 & كحول & مسرح & \\
\hline 5 & 72.3 & 578 & 44.1 & 60.3 & 100 & 100 & 60 & 100 & 100 & 14.1 & ماء & مسرح & \\
\hline 26 & 13.9 & 111 & 25.8 & 85.3 & $\mathbf{0}$ & 0 & 0 & $\mathbf{0}$ & $\mathbf{0}$ & 0 & بدون & فيسكوز & \\
\hline 13 & 65 & 520 & 47.3 & 75.7 & 100 & 100 & 40 & 75 & 66.7 & 15.4 & كحول & فيسكوز & \\
\hline 18 & 56.5 & 452 & 38.1 & 63.5 & 100 & 100 & 20 & 50 & 66.7 & 14.1 & ماء & فيسكوز & \\
\hline 25 & 14.1 & 113 & 31.3 & 81.3 & 0 & $\mathbf{0}$ & 0 & $\mathbf{0}$ & 0 & $\mathbf{0}$ & باون & فبران & \\
\hline 3 & 76.4 & 611 & 67.2 & 32.8 & 100 & 100 & 100 & 100 & 100 & 11.5 & كحول & فبران & \\
\hline 14 & 63.1 & 505 & 61.8 & 30 & 100 & 100 & 60 & 75 & 66.7 & 11.5 & ماء & فبران & \\
\hline 23 & 15.4 & 123 & 27.5 & 95.6 & 0 & 0 & 0 & 0 & 0 & 0 & باون & مسرح & \\
\hline 4 & 74.8 & 598 & 45.3 & 78.9 & 100 & 100 & 60 & 100 & 100 & 14.1 & كحول & مسرح & \\
\hline 12 & 68 & 544 & 49.9 & 81.9 & 100 & 100 & 60 & 75 & 66.7 & 10.3 & ماء & مسرح & \\
\hline 20 & 15.7 & 125 & 29.3 & 95.9 & $\mathbf{0}$ & $\mathbf{0}$ & 0 & 0 & $\mathbf{0}$ & $\mathbf{0}$ & بدون & فبران & \\
\hline 7 & 71.6 & 573 & 42.1 & 74.8 & 100 & 100 & 80 & 100 & 66.7 & 8.97 & كحول & فبران & \\
\hline 10 & 69.4 & 556 & 47.4 & 73.7 & 100 & 100 & 60 & 100 & 66.7 & 7.69 & ماء & فبران & \\
\hline 24 & 14.7 & 117 & 26.4 & 90.8 & $\mathbf{0}$ & $\mathbf{0}$ & $\mathbf{0}$ & $\mathbf{0}$ & $\mathbf{0}$ & $\mathbf{0}$ & باون & فيسكوز & \multirow{3}{*}{ 3: 3} \\
\hline 1 & 78.2 & 626 & 30 & 69.2 & 100 & 100 & 60 & 100 & 66.7 & 100 & كحول & فيسكوز & \\
\hline 16 & 62.6 & 501 & 31.5 & 40.9 & 100 & 100 & 40 & 50 & 66.7 & 71.8 & ماء & فيسكوز & \\
\hline 21 & 15.7 & 125 & 25.3 & 100 & 0 & 0 & 0 & 0 & 0 & 0 & بلدون & مسرح & \multirow{9}{*}{ 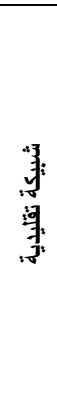 } \\
\hline 2 & 76.7 & 613 & 40.1 & 79.3 & 100 & 100 & 60 & 75 & 66.7 & 92.3 & كحول & مسرح & \\
\hline 6 & 72.2 & 577 & 40.4 & 82.7 & 100 & 100 & 80 & 100 & 66.7 & 7.69 & ماء & مسرح & \\
\hline 22 & 15.6 & 125 & 100 & 24.9 & 0 & 0 & $\mathbf{0}$ & 0 & 0 & 0 & باون & فيسكوز & \\
\hline 15 & 62.8 & 503 & 58.6 & 28.2 & 100 & 100 & 60 & 75 & 66.7 & 14.1 & كحول & فيسكوز & \\
\hline 9 & 70.2 & 562 & 67.2 & 27.8 & 100 & 100 & 80 & 75 & 100 & 11.5 & ماء & فيسكوز & \\
\hline 27 & 13.7 & 110 & 21.7 & 88.1 & 0 & 0 & 0 & 0 & $\mathbf{0}$ & $\mathbf{0}$ & باون & فبران & \\
\hline 11 & 68.7 & 550 & 31.8 & 83.5 & 100 & 100 & 60 & 100 & 66.7 & 7.69 & كحول & فبران & \\
\hline 17 & 58.4 & 467 & 28.9 & 69.8 & 100 & 100 & 40 & 50 & 66.7 & 11.5 & ماء & فبران & \\
\hline
\end{tabular}

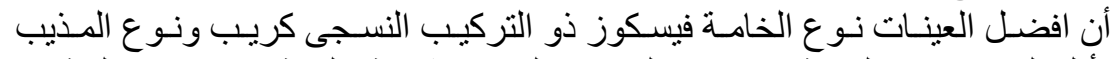

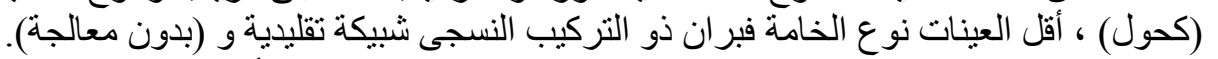

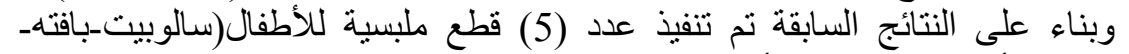

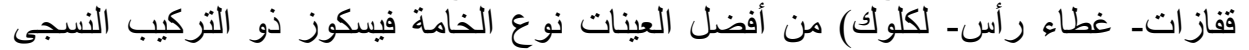

$$
\text { كريب ونوع المذيب (كحول) . }
$$


مجلة الاقتصاد المنزلي - مجلد 28 - العدد الرابع 2018

القطع المنفذة من ملابس الاطفال من القماش الأي حقق افضل النتائج
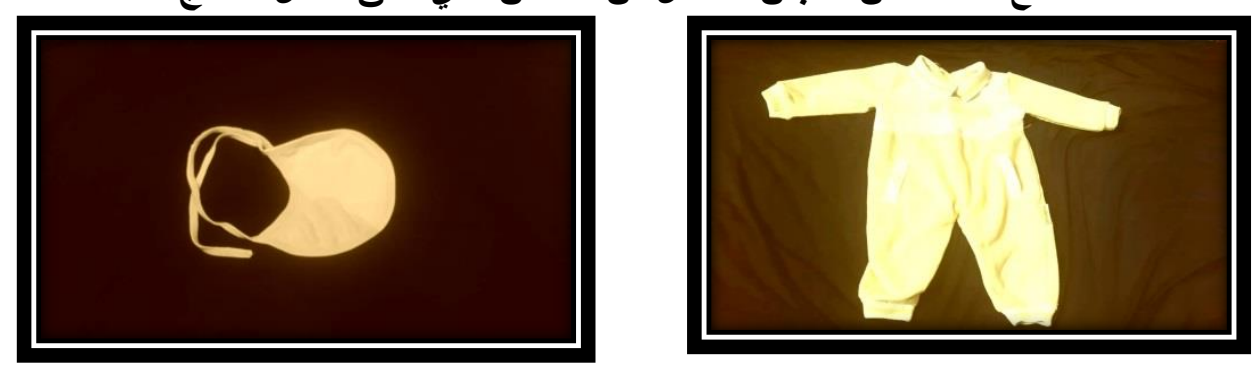

صورة (1) توضح سالوبيث أطفال حديثي الولاده صورة (2) توضح بافتة أطفال حديثي الولاده
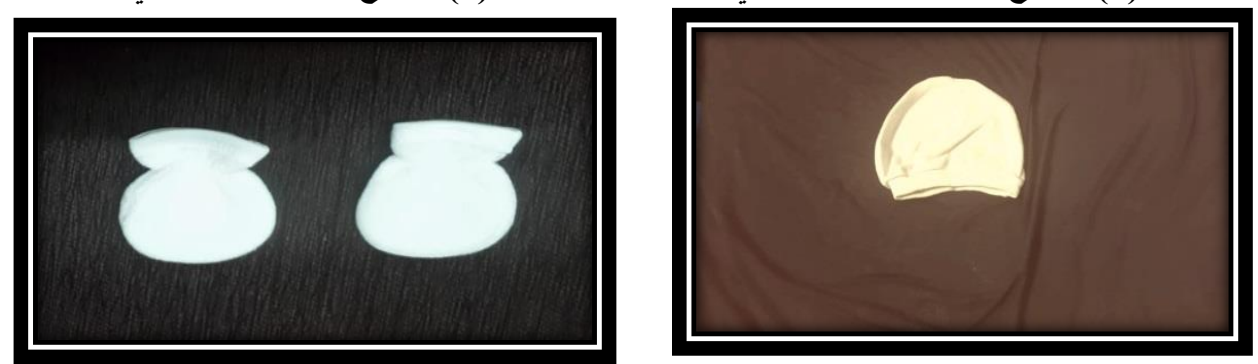

صورة (3) توضح غطاء رأس أطفال حديثي الولاده صورة (4) توضح قفازات أطفال حديثي الولاده

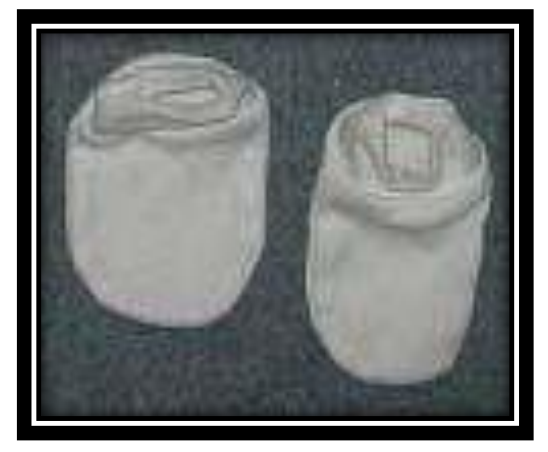

صورة (5) توضح لكلوك أطفال حديثي الولاده

• استخدام الصبغات المستخدمة في البحث وكذللك الخامات التي حققت نتائج ضبط في ملابس الاطفال.

• البحث الدائم عن مواد صديقة للبيئة من خلال دراسات منتوعة في مجال الملابس

• زيادة التعمق في معالجة الاقمشة والسعي وراء الحصول على أقششة متعددة

الوظائف.

• الاختيار الدقيق للخامات التي تعطي جودة عالية أثناء عمليات المعالجة. 


\section{مجلة الاقتصاد المنزلي - مجلد 28 - العدد الرابع 2018}

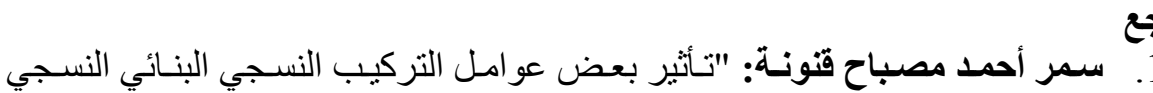

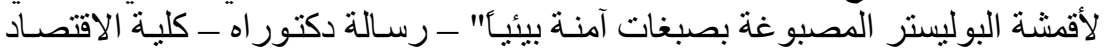

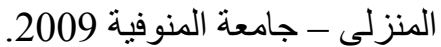

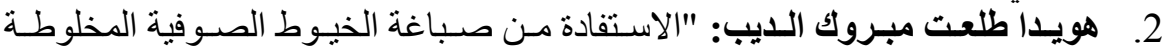

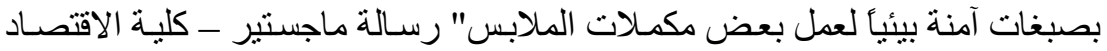
المنزلي - جامعة المنوفية - 2014.

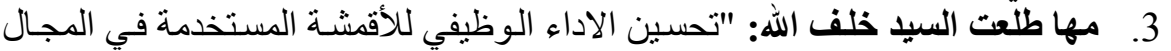

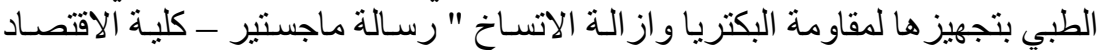

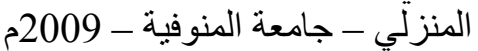

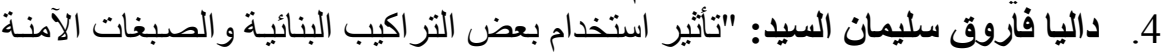

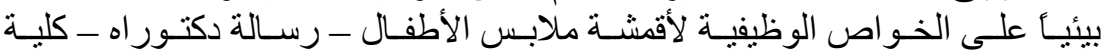

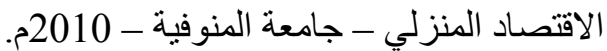

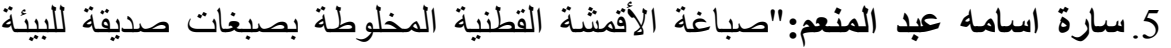

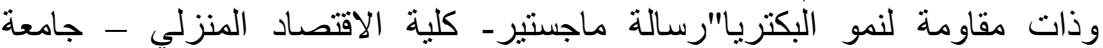

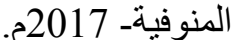

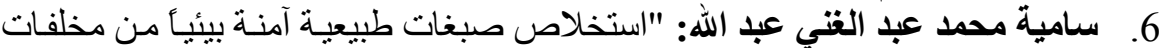
نبات الفول وتطبيقها في مجـال الملابس" عيس رسالة دكتور اه ـ كلية الاقتصـاد المنزلي-

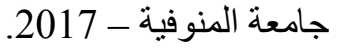

7-S. Isharat Ali : "Revival of Natural Dyes In Asia" - J .Soc Dyers And Colourist - Vol .Log - 1993 .

8-V .KGupta ; RAsachan : "Natural Dyes The Indian Textile -Journal May - 1998.

9- John and margartconnon "Dye plants and Dying" 1994.

10- Fleischer Guenter "Back to nateral dyes"- Colourage April- 1995. 


\title{
مجلة الاقتصاد المنزلي - مجلد 28 ـ العدد الرابع 2018
}

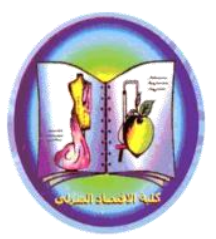

The $6^{\text {th }}$ international- $20^{\text {th }}$ Arabic conference for Home Economics

Home Economics and Educational quality assurance December 23rd -24th, 2018

Journal of Home

Economics

http://homeEcon.menofia.edu.eg

ISSN 1110-2578

Benefiting From Processing Multifunctional Fabrics With

Eco-Friendly Materials In The Implementation Of Children's Cloths

\section{Magda Ebrahim , Eman Raafat}

Lecturer, Clothes and Textile Department- Faculty of Home Economics- Menoufia University

\begin{abstract}
Today, most of the research aims to encourage the use of clean technology to reduce pollution of the environment . Natural dyes were one of the most important trends in order to reduce the pollution of dyes to optain a product that is safe and does not affect human health and does not harm environment in its manufacturing stages .so the study aimed to benefit from fabrics treated with enviromentally friendly materials lemon peel extracts in children's clothes and to determine the best condition for the treatment of fabrics to obtain the highest levels of color stability, the samples were dyed at home after that laboratory tests were conducted (color,washing, sweat, friction ,the strength of tensile and elongation of fabrics ) At National institute of calibration labs And five pieces of children's clothes were carried out And the research found that The best samples are the Viscose material with the crepe texture and the type of solvent (alcohol). The lowest samples are the type of fibran material with the traditional structure and (without treatment).
\end{abstract}

